\title{
AVALIAC̣ÃO DE IMPACTO DO PROGRAMA BOLSA FAMÍLIA SOBRE A EDUCAÇÃO DOS JOVENS*
}

\author{
Nayara Abreu Julião \\ Flávia Chein
}

\begin{abstract}
The aim of this article is to evaluate the impact of Bolsa Familia Program (BFP), a Brazilian conditional cash transfer program, on the schooling, school attendance and approval of young people aged 15-25 years old from beneficiary families. Based on data from National Household Survey (Pesquisa Nacional por Amostra Domiciliar - PNAD) for the years 2003, 2004, 2008 and 2012, we adopt a difference-in-difference approach to estimate the effects of BFP on education. Opposite to previous results on child education, the estimates show that $\mathrm{BFP}$ is no effective in stimulating the human capital accumulation, considering the young people.

KEY WORDS | Conditional Cash transfer; Bolsa Familia; Education; Young People

RESUMO | O objetivo deste artigo é avaliar o impacto do programa de transferência de renda condicionada Bolsa Família sobre a escolaridade, frequência escolar e aprovação dos jovens entre 15 e 25 anos das famílias beneficiadas. O método utilizado na investigação foi o diferenças em diferenças, e os dados são provenientes da Pesquisa Nacional por Amostra Domiciliar (PNAD) para os anos de 2003, 2004, 2008 e 2012. Contrariamente a resultados anteriores sobre educação de crianças, as estimativas mostram que o PBF não é efetivo em estimular de maneira significativa a acumulação de capital humano nos jovens das famílias beneficiárias, os impactos sobre estes são muito tênues ou de pouca magnitude.
\end{abstract}

PALAVRAS-CHAVE | Transferência de renda; Bolsa Família; Educação; Jovens

Os autores agradecem ao apoio financeiro recebido pela FAPEMIG, Edital Demanda Universal 2012, e ao CNPq, Edital Ciências Sociais Aplicadas e Universal 2011, e bolsa de produtividade 2013-2015. 



\section{INTRODUC̣ÃO}

Os programas de transferência condicional de renda implantados na América Latina a partir da década de 1990 são considerados a principal estratégia de política pública de proteção social, visando à promoção do desenvolvimento social. Além de promoverem o acesso a serviços públicos básicos como saúde, educação e proteção social, os programas contribuem para o alívio imediato da pobreza através da transferência direta de uma quantia monetária às famílias, e o estímulo ao capital humano com base no cumprimento das condicionalidades exigidas como contrapartida ao benefício.

O debate sobre a necessidade de implementar programas de transferência de renda tem como diretrizes a erradicação da pobreza e redução da desigualdade. Por meio das condicionalidades, focalizadas principalmente nas crianças, os programas buscam proporcionar melhorias nas condições de vida das famílias pobres, inserindo-as no sistema econômico e contribuindo para a redução da pobreza entre gerações mediante o acesso às políticas de saúde e educação.

Honduras foi o primeiro país a implantar um programa de transferência de renda em 1990, com o Programa de Asignación Familiar, a partir de então diversos países passaram a adotar programas semelhantes: no México, Oportunidades; na Colômbia, Familias em Acción; no Chile, Chile Solidário; Costa Rica, Avancemos; Equador, Bono de Desarrollo Humano; República Dominicana, Solidaridad; El Salvador, Red Solidaria; Peru, juntos. De acordo com dados da Comissão Econômica para America Latina e Caribe (CEPAL), ao todo 18 países da região operam programas de transferência condicional de renda.

No Brasil, o programa Bolsa Família criado em outubro de 2003, pelo Governo Federal com o objetivo inicial de reduzir a pobreza extrema e melhorar a distribuição de renda no país, surge 
como unificação dos seguintes programas de transferência de renda: Bolsa Escola, Bolsa Alimentação, Cartão Alimentação e Auxílio-Gás. O PBF é um programa de transferência de renda com condicionalidades, voltado para famílias extremamente pobres e famílias pobres classificadas segundo uma faixa de renda familiar per capita mensal.

Atualmente atende a mais de 13,8 milhões de famílias em todo território nacional segundo informações do Ministério do Desenvolvimento e Combate a Fome, isso corresponde a aproximadamente um quarto da população brasileira, sendo considerado o programa de maior cobertura da América Latina.

Desde sua criação instalou-se um amplo debate sobre o potencial do programa em cumprir seus principais objetivos, quais eram, reduzir a pobreza e promover a queda da desigualdade de renda existente no Brasil. Estudos apontam para impactos positivos nesse sentido. Soares et al. (2007) argumentam que a redução da desigualdade no Brasil nos últimos anos, embora seja decorrente de uma série de causas, se deve também ao programa de transferência de renda. Costa e Salvato (2008) analisam o período de 2004 a 2006 e encontram um impacto de $20 \%$ na redução da pobreza e 2,04\% na redução da desigualdade, em que famílias que sofrem maior impacto pelo programa são aquelas denominadas indigentes, entretanto os autores argumentam que a focalização do programa é razoável, apresenta baixa cobertura, mas em compensação também apresentou baixo vazamento. Corroborando com esses resultados, Tavares et. al.(2009) também demonstram que o programa é efetivo no combate à extrema pobreza e redução da desigualdade, e acrescentam que a magnitude do impacto varia positivamente com seu grau de focalização.

Ao longo desses dez anos, o programa vem quebrando mitos e superando as expectativas. A polêmica diante da opção de operar com repasse de benefícios monetário às famílias foi grande, havia uma preocupação corrente de que as famílias não usariam o benefício de forma adequada. Entretanto, a experiência mostrou o contrário, um estudo realizado pelo Instituto Brasileiro de Análises Sociais e Econômicas (Ibase) em 2008 revelou que alimentação, material escolar e vestuário são os itens em que as famílias mais gastam o benefício mensal. O mito de que as famílias beneficiadas passariam a ter mais filhos para ter acesso a um maior volume de recursos, também não se concretizou, ao contrário, há uma tendência de declínio da taxa de fecundidade da população brasileira, e a redução recente tem sido maior justamente entre os mais pobres. Um terceiro mito, e talvez o mais propagado, diz respeito à "acomodação das famílias beneficiadas", Jannuzzi e Pinto (2013) mostram que os indicadores são muito próximos entre beneficiários e não beneficiários do programa, no que tange em termos de ocupação, procura de emprego ou jornada de trabalho.

No que diz respeitos aos impactos das condicionalidades dos programas de transferência de renda, a literatura aponta para um aumento expressivo da taxa de matrícula e redução do abandono, sendo o programa, portanto, eficaz no sentido de possibilitar o acesso à educação. Os 
trabalhos de Silva, Brandão e Dalte (2011), Cacciamali, Tatei e Batista (2011), Fahel, Morais e França (2011), Glewwe e Kassouf (2008), Camargo (2011), Pellegrina (2011), Oliveira e Soares (2013), Cireno, Silva e Proença (2013), e uma pesquisa realizada pelo INEP e MEC (2011), mostram resultados importantes do impacto do programa sobre a condicionalidade no tocante à educação.

O objetivo deste artigo é analisar o impacto do programa Bolsa Família sobre a educação de jovens entre 15 e 25 anos de idade, procurando observar se, além dos benefícios gerado às crianças, houve ao longo dos anos um estimulo aos demais jovens das famílias beneficiadas. Embora exista uma vasta bibliografia a respeito do impacto do programa de transferência condicional de renda sobre o aumento da frequência escolar e redução do abandono por parte das crianças beneficiadas, ainda sabemos pouco sobre se esses programas contribuem também no sentido de manter e elevar o acesso à população jovem das famílias beneficiadas.

Com base em dados da Pesquisa Nacional por Amostra Domiciliar (PNAD), analisa-se a evolução da escolaridade da população jovem ao longo dos anos de 2003, 2004, 2008 e 2012, comparando beneficiários e não beneficiários do programa Bolsa Família, a fim de verificar se houve aumento do capital humano e qual o impacto do programa sobre a taxa de aprovação e frequência escolar da população jovem das famílias beneficiadas.

\section{REVISÃO DE LITERATURA}

\subsection{Os programas de transferência de renda na América Latina}

Historicamente, os países da América Latina se caracterizam por grande concentração de renda e elevado nível de pobreza. A despeito dos avanços na última década em alguns países, a região ainda se mantém como a mais desigual do mundo no que diz respeito às desigualdades de renda, acesso a serviços e educação.

A partir da década de 1960, países como Brasil, Chile e México experimentaram um expressivo crescimento econômico através do processo de industrialização por substituição de importações. No entanto, esse desenvolvimento nos países periféricos não permitiu um crescimento com equidade, apresentando pouco êxito nas reduções das desigualdades (Soares, et al., 2007). O início do processo de industrialização não foi acompanhado de políticas sociais e econômicas voltadas para a distribuição de renda e inserção da população pobre no mercado de consumo, e a urbanização acelerada e desordenada acabou por acentuar as desigualdades.

Ao fim do período desenvolvimentista, no final dos anos 70 e início dos 80, a desestabilização do crescimento, somada à combinação de dívida externa e dívida interna associada à inflação 
trouxeram redução no nível de bem-estar da sociedade, contribuindo ainda mais para o aumento da pobreza e desigualdade social (Reis e Nascimento, 2009).

A pobreza se institui como questão social com o surgimento das grandes cidades, as famílias recém-chegadas do campo em condições extremamente precárias, inspiravam preocupação e receio, suscitando intervenções do meio público em prol da instituição de uma nova ordem social (Lavinas, 2002). Hoje, a maioria das famílias pobres vive nas áreas urbanas e zonas metropolitanas, o que torna o caráter da pobreza eminentemente urbano, uma vez que a reprodução da pobreza é medida pela reprodução do modo urbano das condições de vidas dessas famílias. Melhorar as condições de bem-estar de uma sociedade é fundamental para reduzir as carências materiais e não materiais e reduzir os riscos de vulnerabilidade intergeracional, quebrando o círculo vicioso da pobreza, famílias pobres, de baixa escolaridade, desempregadas ou subempregadas que tendem a repetir isso entre gerações.

Nas décadas mais recentes, a pobreza cedeu lugar à exclusão social. A pobreza absoluta pode ser definida como ausência ou privação de recursos para satisfazer necessidades básicas, como nutrição, moradia, entre outros, por meio da renda. Já a condição de exclusão social lhe é imputada do exterior e deriva de rupturas com os vínculos sociais, que resultam em sentimentos de rejeição, perda de identidade e falência dos laços comunitários e sociais.

Surge um desafio para a governabilidade urbana, que exige dos governos locais uma ação rápida e efetiva para a inclusão dos indivíduos deixados às margens ou fora do sistema econômico de mercado. Atualmente, os pobres e excluídos constituem o principal público-alvo dos programas de transferência de renda de caráter focalizado. São políticas implantadas com duplo objetivo, a saber, liberar os cidadãos da miséria, e oferecer-lhes o mínimo de independência econômica necessário para o desenvolvimento e respeito de si, oferecendo instrumentos para promover autonomia individual e criar um senso de comunidade, sendo instrumentos de cidadania (Leão e Pinzani, 2013).

Os programas de transferência condicional de renda criados na América Latina a partir da década de 90 se destacam como estratégia política de combate à pobreza e redução da desigualdade, e consistem na distribuição direta de renda a famílias pobres, articulados à contrapartidas nas áreas de saúde e educação. O repasse de uma quantia monetária às famílias tem como objetivo o alívio imediato da pobreza no curto prazo, enquanto o compromisso criado entre o Estado e as famílias para o cumprimento das condicionalidades visa a quebra do ciclo de pobreza no longo prazo. Busca-se assim, através dessa nova geração de política social baseada em condicionalidades, a inserção da população pobre no sistema econômico, garantindo-lhes um nível mínimo de renda para a subsistência e acesso aos serviços públicos básicos como saúde, educação e assistência social. O pressuposto é que crianças com melhores condições de saúde e educação possam aumentar suas oportunidades de desenvolvimento social, tendo melhores oportunida- 
des que seus pais, objetivando assim uma quebra no ciclo de pobreza entre gerações a longo prazo, contribuindo para uma redução no nível de desigualdade de gerações futuras.

Há quem critique os programas de transferência condicional de renda argumentando que são de caráter meramente assistencialista, com incentivos a dependência, e transferem recursos de usos mais eficientes sem exercerem, no entanto, impactos reais na economia. Entretanto, segundo Cavalcanti (2011), essas políticas vêm ganhando destaque em função de seus impactos na melhoria dos indicadores sociais, como aumento da frequência escolar, redução da desnutrição e ampliação no acompanhamento da saúde, além dos reflexos na redução da pobreza e desigualdade. De acordo com Cohn (2004), não se deve entender os programas como mera transferência de renda, mas como forma de permitir a inclusão dos cidadãos de baixa renda na sociedade.

Honduras foi o primeiro país a implantar um programa de transferência de renda em 1990, com o Programa de Asignación Familiar (PRAF), que propunha melhorar os efeitos das políticas estruturais sobre as famílias mais pobres, garantindo uma renda para manutenção do consumo das famílias, ou pelo menos permitindo que não caísse abaixo de um nível crítico. O programa sofreu algumas reestruturações ao longo dos anos, a primeira, em 1998, quando passou a se chamar PRAF/BID fase II, que vigorou até 2005, e passou a ter como objetivo o investimento em capital humano, tendo como condicionalidades a frequência escolar e visitas aos centros de saúde. De 2006 a 2009, foi substituído pelo PRAF/BID fase III. E, em 2010, foi criado o Bono 10.000 Educación, Saludy Nutrición, promovendo estratégias de ação intersetorial para a educação, saúde e nutrição, bem como a coordenação com outros programas sociais estimulando o emprego, renda e poupança das famílias em situações de pobreza e extrema pobreza, criando oportunidades para a elevação do padrão de vida e integração na sociedade (Reis e Magro, 2011). O programa aponta impactos positivos sobre as condicionalidades, segundo Glewwe e Olinto apud Santarrosa (2011) o programa exerceu impacto de 3\% no aumento da matrícula escolar.

No México, foi lançado, em 1997, o Programa de Educação Saúde e Alimentação (PROGRESA), atendendo prioritariamente famílias que residiam em áreas rurais com acesso às escolas e postos de saúde de modo que pudessem ser cumpridas as contrapartidas do programa referentes à frequência escolar e visitas aos postos de saúde. Renomeado em 2001 para Oportunidades passou a incluir também famílias consideradas em extrema pobreza residentes em áreas urbanas, atendendo aproximadamente a cinco milhões de famílias no ano de 2004. A escolha das famílias se dá através de uma seleção dos municípios quanto ao índice de marginalidade econômica e social, sendo $90 \%$ dos domicílios selecionados nos municípios com altos índices, enquanto apenas 6\% são selecionados nos municípios com índices de marginalidade mais baixos. Os benefícios se dividem em três categorias, uma incondicional e duas condicionais. O primeiro corresponde ao repasse de $\$ 250$ pesos (USD 18.80) para idosos. Já os benefícios condicionais consistem em uma transferência de renda de $\$ 189$ pesos (USD 14.20) para compra de alimentos e como con- 
trapartida é exigida a presença da mãe da família beneficiada em palestra sobre nutrição e saúde, e o outro benefício condicional diz respeito à frequência escolar e visitas aos postos de saúde de jovens no período escolar. Os benefícios variam de $\$ 120$ a $\$ 760$ (USD 9.02 a USD 57.14) pesos de acordo com a série cursada e o sexo do aluno, com um limite máximo de $\$ 1.855$ pesos (USD 139.47) para famílias com menos de um filho no segundo ciclo da educação secundária. Os recursos são transferidos a cada dois anos e se prioriza as mães das famílias como responsáveis pelo recebimento do benefício. O programa atesta uma ótima focalização e também apresenta impactos sobre a redução da desigualdade (Soares et. al, 2007). No que diz respeito às condicionalidades, Schultz (2004) apud Pellegrina (2011) encontra um impacto positivo na taxa de matrícula, sendo o efeito maior em crianças com 4 a 6 anos de educação e do sexo feminino.

O Familias em Acción na Colômbia criado no ano 2000 foi reelaborado em 2006 e se propôs a contribuir com a redução da pobreza e desigualdade de renda, promovendo o aumento do capital humano, e melhorando as condições de vida das famílias pobres e vulneráveis através de um suplemento de renda. Tem como público alvo famílias com crianças menores de 18 anos. O processo de seleção leva em consideração condições de vida dos indivíduos e características dos domicílios. Há dois tipos de benefícios, um nutricional para famílias com crianças menores de sete anos, e um escolar para famílias com crianças com idade entre 7 e 18 anos matriculados no ensino primário e secundário. As contrapartidas consistem na frequência mínima de $80 \%$ das crianças de 7 a 18 anos, visitas às clínicas de saúde que variam de acordo com a idade, e a participação da mãe da família beneficiada aos encontros e sessões de treinamentos organizados no nível municipal. O programa atendia a aproximadamente 2,8 milhões de famílias até 2010 (Cavalcanti, 2011). Quanto à educação, o programa apresenta um impacto de $2 \%$ no aumento da matrícula escolar, Attanasio et al. apud Santarrosa (2011).

O programa Chile Solidário, criado em 2002, é um componente do programa Puente, por meio do qual é realizada a transferência monetária. Ao ingressarem no programa, as famílias passam a receber apoio dos assistentes sociais para o cumprimento das condicionalidades estabelecidas. Como contrapartida ao recebimento da renda está a frequência escolar semanal, a participação em programas de nutrição, e visitas aos postos de saúde. O programa tem duração máxima de dois anos e redução do benéfico a cada semestre, sendo $\$ 10500$ pesos (USD 19.36) nos primeiros seis meses, chegando a $\$ 3716$ (USD 6.85) pesos nos últimos seis meses. Estudos mostram uma boa focalização do programa, entretanto apontam para a baixa contribuição do programa sobre a desigualdade social, que pode ser atribuído ao baixo número de beneficiários, e baixo valor das transferências, que não chegam a atingir $0,01 \%$ da renda total (Soares et. al., 2007; Cavalcanti, 2011). Quanto às condicionalidades, Galasso apud Santarrosa (2011) conclui que o programa elevou as matrículas em $7 \%$.

A implantação de programas de transferência de renda tem sido acompanhada de esforços sistemáticos para medir sua eficácia e compreender seu impacto sobre o comportamento das 
famílias. Como se pode ver, um dos pontos em comum entre os programas é o foco nas crianças, sendo necessário o acompanhamento das condições estabelecidas como pré-requisitos para que as famílias sejam contempladas. A expectativa é de que as crianças acompanhadas cumpram adequadamente o ciclo de educação básica e tenham acompanhamento de saúde no período de gestação e nos primeiros anos de vida. As políticas de educação e de inclusão socioprodutiva, com destaque para o investimento em capital humano ao longo prazo, são chaves para romper o ciclo de pobreza mantida entre gerações e para promoção da igualdade.

No que tange à educação, muitos trabalhos têm verificado resultados positivos, embora os impactos variem muito entre as regiões, de uma forma geral observa-se um aumento na taxa de matrícula das crianças beneficiadas.

Tendo os programas aumentado o acesso à escola, faz-se necessário saber se o benefício se reflete também na manutenção dessas crianças na escola para que o objetivo das condicionalidades que visam melhorar o desenvolvimento social dos beneficiários através da educação seja atendido. Em outras palavras, queremos saber se aquelas crianças atendidas pelo programa ainda permanecem na escola, e se o programa possibilitou o acesso às escolas de outros jovens do grupo familiar.

Assim, a questão central que motivou o trabalho é saber se os programas de transferência condicionada de renda, com foco no programa Bolsa Família, constituem uma política social adequada, para, além do alívio imediato da pobreza, possibilitar um melhor rendimento entre os jovens das famílias beneficiárias, ou seja, dado um aumento da renda familiar qual o estímulo dos jovens e adultos em se manter ou, até mesmo retornar às escolas, nos casos onde houve abandono escolar.

\subsection{Políticas sociais no Brasil}

As políticas sociais no Brasil têm sua origem estreitamente ligada ao desenvolvimento urbano industrial. $\mathrm{O}$ avanço industrial aliado à expansão urbana agravou as desigualdades sociais, com grandes aglomerados em torno das cidades, que atestavam o crescimento da pobreza, do desemprego e da exclusão com privações social, econômica, cultural e política para a classe trabalhadora.

No período de 1930 a 1960 observa-se o desenvolvimento de políticas sociais voltadas para a "proteção" do trabalhador, com o objetivo de criar condições para garantir a força de trabalho adequada, atendendo às ordens do mercado vigente. Há de se considerar que a política social foi produto de muitas lutas por parte dos trabalhadores reivindicando suas necessidades. No entanto, o sistema de proteção social oferecia cobertura reduzida, deixando de fora aqueles 
que mais necessitavam. Os pobres ainda eram excluídos em razão de seus vínculos instáveis e precários com o mercado de trabalho, "Não sendo um grupo de pressão, sem posição sócioocupacional definida, as camadas pobres da população jamais foram sistemática e regularmente beneficiadas" (Lavinas, 2003).

No período da ditadura militar passava-se a idéia de que o desenvolvimento social seria decorrente do desenvolvimento econômico. Durante essa época marcada pela expansão da produção, modernização e entrada do capital estrangeiro, as políticas sociais apresentavam caráter meramente assistencialista e clientelista. Somente com o advento da Constituição de 1988, o conjunto do sistema de seguridade social - previdência, saúde pública e assistência - se torna foco prioritário das reformas estruturais (Lavinas, 2003). A preocupação com direitos do cidadão foi claramente uma resposta dada ao período anterior da ditadura militar. Considerada a mais completa entre as constituições brasileiras, com destaque para vários aspectos que garantem o acesso à cidadania, até a primeira metade da década de 1990 ainda deixava sem cobertura a população pobre em idade ativa e com capacidade produtiva.

Os programas de transferência condicionada de renda, como o Bolsa Família, representam uma ruptura com a trajetória do sistema de proteção social brasileiro, fundamentalmente voltado para a concessão de benefícios para aqueles que perderam a capacidade produtiva, incluindo pessoas em idade ativa com um definitivo viés pró-criança. $\mathrm{O}$ valor dos benefícios pagos deixa clara a natureza complementar e não substitutiva da transferência de renda, que supõem algum tipo de capacidade produtiva (Paiva, Falcão e Bartholo, 2013).

\subsection{0 programa Bolsa Família no Brasil e os impactos sobre a educação}

O Programa Bolsa Família, criado em 2003 no Brasil, é considerado o principal programa de transferência de renda da América Latina com maior número de beneficiários, atendendo a 13,8 milhões de famílias em todo território nacional. A criação do programa Bolsa Família teve por finalidade unificar os projetos de âmbito federal adotados até então, como o Programa de Erradicação do Trabalho Infantil (PETI) criado em 1996, centrado na transferência monetária às famílias carentes, buscando eliminar o trabalho infantil estimulando a inserção de crianças na escola; o programa Bolsa Escola de 2001, que concedia às famílias com renda per capita abaixo de $\mathrm{R} \$ 90,00$ um benefício de $\mathrm{R} \$ 15,00$ por criança, com um teto de $\mathrm{R} \$ 45,00$ por família, em contrapartida, as crianças de 6 a 15 anos deveriam estar matriculadas na rede escolar; o Bolsa Alimentação, também criado em 2001, passou a estabelecer a complementação da renda de mães gestantes, em fase de amamentação e com crianças entre 0 e 6 anos de idade, em contrapartida as famílias deveriam atualizar o cartão de vacina das crianças e visitar regularmente o posto de saúde para o pré-natal e o acompanhamento do período de amamentação; e o auxílio Gás, o único sem condicionalidade, onde era concedido às famílias que 
já pertenciam aos demais programas de transferência de renda a quantia de $\mathrm{R} \$ 7,50 /$ mês para ajudar no orçamento doméstico, motivado pela retirada do subsídio aos derivados do Petróleo na época.

A unificação dos programas permitiu a ampliação dos beneficiários e a articulação e consolidação da rede de proteção social no país. A gestão do programa Bolsa Família é descentralizada e compartilhada por União, estados, Distrito federal e municípios. À União, através do Ministério do Desenvolvimento Social e Combate à Fome (MDS) cabe a gestão do PBF em nível estadual e federal, o repasse de recursos para financiamento do programa e a operacionalização do Cadastro Único para programas sociais que permite fazer um levantamento das condições socioeconômicas do grupo familiar sendo utilizado para fazer a seleção das famílias em situações de vulnerabilidade. Por sua vez, os Estados possuem o papel de apoio aos municípios na implementação do programa com foco nas atividades produtivas; na esfera federal, os ministérios da Saúde e da Educação são responsáveis pelo acompanhamento do cumprimento das condicionalidades; e os municípios são responsáveis pela gestão local do programa e cabe à prefeitura indicar o órgão responsável pelo acompanhamento social e cadastro das famílias no Cadastro Único $^{1}$, mantido pela Caixa Econômica Federal que realiza o pagamento do benefício através do Cartão Social emitido para o responsável familiar (BRASIL, 2013).

De acordo com o MDS, os objetivos do programa são o alívio imediato da pobreza através da transferência direta de renda à família, o reforço ao exercício de direitos sociais básicos nas áreas da saúde e educação, por meio das condicionalidades que permitem às famílias romperem o ciclo de pobreza entre gerações, e o desenvolvimento das famílias com programas complementares de modo que consigam superar a situação de vulnerabilidade e pobreza.

Para o recebimento do benefício são considerados a renda per capita mensal da família, o número de crianças e adolescentes até 17 anos e a existência de gestantes e nutrizes. O programa atende às famílias em duas faixas de renda: com renda mensal per capita de até $\mathrm{R} \$ 70,00$ consideradas em situação de extrema pobreza e aquelas com renda mensal de até $\mathrm{R} \$ 140,00$ por pessoa, entendidas como pobres. O Ministério do Desenvolvimento Social e Combate à Fome (MDS) trabalha com quatro tipos de benefícios: o Benefício Básico, de R $\$ 70,00$, pago às famílias consideradas extremamente pobres, independente da composição familiar; o Benefício Variável, no valor de R\$ 32,00 concedido às famílias extremamente pobres e famílias pobres que tenham crianças e adolescentes de até 15 anos, gestantes e/ou nutrizes com um teto de até cinco benefícios variáveis, ou seja, um máximo de R \$160,00 por família; o Benefício Variável Vinculado ao Adolescente (BVJ) no valor de $\mathrm{R} \$ 38,00$, pago às famílias pobres e extremamente pobres que possuam adolescentes de 16 e 17 anos, matriculados na escola, podendo acumular até dois benefícios, um total

1 O Cadastro Único para programas sociais do Governo Federal (CadÚnico) é um instrumento que identifica e caracteriza famílias de baixa renda, entendidas como aquelas que têm renda mensal de até meio salário mínimo por pessoa ou renda mensal total de até três salários mínimos. 
de R \$ 76,00 por família; e o Benefício Variável de Caráter Extraordinário (BVCE) pago às famílias nos casos em que a migração dos programas Auxílio-Gás, Bolsa Escola, Bolsa Alimentação e Cartão Alimentação para o Bolsa Família cause perdas financeiras - o valor do benefício varia em razão do cálculo realizado a partir da renda per capita da família e do benefício já recebido no PBF.

Como se trata de um programa de promoção da família, é necessário que a família beneficiada cumpra as condicionalidades do programa que são: na área da saúde, o acompanhamento do cartão de vacinação, o crescimento e desenvolvimento das crianças menores de 7 anos, acompanhamento das mulheres na fase de 14 a 44 anos, pré-natal e acompanhamento da saúde do bebê, se gestantes ou nutrizes; na área da educação, todas as crianças entre 6 e 15 anos devem estar matriculadas na rede escolar e com frequência escolar mensal mínima de $85 \%$ da carga horária, já para estudantes entre 16 e 17 anos é exigida uma frequência mínima de 75\% da carga horária; na área da assistência social, as crianças em riscos ou retiradas do trabalho infantil pelo Programa de Erradicação do Trabalho Infantil (PETI) devem participar dos Serviços de Convivência e Fortalecimento de Vínculos realizados pelo próprio programa.

Nesse sentido, o não cumprimento das condicionalidades resulta em sansões que vão desde advertência à família podendo chegar à suspensão do benefício. No primeiro descumprimento, a família receberá apenas uma advertência. No segundo descumprimento, o benefício fica retido por 30 dias, mas é repassado o acumulado no mês seguinte, no caso do BVJ, no segundo registro o benefício será suspenso por 60 dias. No terceiro descumprimento o benefício é suspenso por 60 dias, no caso do benefício BVJ, esse terceiro descumprimento já gera o cancelamento do benefício ao jovem. No quarto descumprimento o benefício continua suspenso por 60 dias, porém não é mais repassado posteriormente. E por último ao quinto registro de descumprimento a família poderá ser desligada do programa.

Aquelas famílias em situações de maior vulnerabilidade, que encontram dificuldades para o cumprimento das condicionalidades, ocasionado pelos obstáculos em acessar os serviços e benefícios sociais de que necessitam, deverão buscar orientações com o gestor municipal do programa Bolsa Família, procurar o Centro de Referência de Assistência Social (Cras), o Centro de Referência Especializado de Assistência Social (Creas) ou a equipe de assistência social do município. O objetivo é oferecer ajuda às famílias para que sejam superadas as dificuldades, afim de não causarem o cancelamento do benefício já que geralmente se tratam das que mais necessitam dele.

A educação é essencial para o desenvolvimento do indivíduo nas relações sociais e inserção nos meios culturais, sociais e produtivos da sociedade contemporânea. $\mathrm{O}$ acesso à escola é um direito assegurado a todas as crianças e adolescentes e deve ser proporcionado pelo Estado, entendido como forma de superação dos riscos sociais e inclusão das famílias em situações de vulnerabilidade. Nesse sentido, o programa busca induzir as famílias à busca pelo acesso e permanência das crianças e adolescentes no sistema de ensino escolar através da condicionalidade na área da educação. 
Os estudos aqui apresentados corroboram quanto aos resultados dos impactos positivos sobre o aumento na taxa de matrícula e redução da evasão. Quanto ao impacto sobre desempenho, os resultados não parecem tão otimistas, exercendo pouco ou nenhum impacto sobre os beneficiários.

Silva, Brandão e Dalte (2009), numa pesquisa para as famílias residentes no Nordeste, mostram que há uma relação entre o nível de escolaridade dos pais e o nível de escolaridade das crianças, que tendem a repetir a trajetória escolar dos pais, confirmam também que o número de nascimentos decresce conforme aumenta a escolaridade do responsável legal do PBF. A pesquisa aponta, ainda, para uma taxa de cobertura escolar entre os jovens de 7 até 15 anos de 95,4\%, o que induz um impacto positivo do programa sobre a educação, uma vez que $26 \%$ dos entrevistados informaram que havia crianças fora da escola antes de receberem o benefício. O principal motivo do afastamento escolar por parte dos beneficiários é a dificuldade de conciliar a rotina dos estudos com o trabalho $(33 \%)$, seguido pela falta de vontade $(17 \%)$ e, por último, a gravidez $(13,1 \%)$.

Cacciamali, Tatei e Batista (2008) analisam o impacto do PBF sobre a incidência de trabalho infantil e a frequência escolar das crianças de famílias pobres no Brasil, em 2004, período anterior à grande expansão do programa. Os autores chegam à conclusão de que, entre os domicílios pobres, $85 \%$ dos jovens apenas estudam, 1,7\% apenas trabalham e 9,1\% estudam e trabalham. O maior efeito do PBF é a redução de 2,5\% na probabilidade da criança não estudar e não trabalhar, chegando a 4\% na área rural. Em relação à frequência escolar, apontam para o fato de que o tamanho da família e os aumentos na idade da criança têm impactos negativos ao acesso escolar, enquanto o maior nível de escolaridade dos pais e aumentos da renda domiciliar per capita, bem como o recebimento do PBF aumentam as chances das crianças frequentarem a escola. O trabalho aponta, porém, para um impacto negativo do Programa sobre a incidência do trabalho infantil, indicando que ser beneficiário do programa eleva as chances de exercer o trabalho infantil nos domićlios pobres, uma vez que o programa não apresenta atividades extracurriculares de modo que fossem reduzidas as horas em que as crianças poderiam se dedicar ao trabalho.

Fahel, Morais e França (2012) discutem os impactos do programa sobre a matrícula escolar dos beneficiários entre 6 e 17 anos no estado de Minas Gerais. Utilizando dados da PAD/2009², estimam, pelo método de "Propensity Score Matching", os impactos do PBF na matrícula escolar de crianças e jovens, desagregados por idade, sexo, raça/etnia e situação censitária. A diferença em relação à taxa de matrícula é de 2,1\% a 2,6\% a favor dos beneficiários. A taxa de matrícula é menor no ensino médio se comparado ao ensino fundamental, bem como as taxas de evasão e reprovação também são maiores. A diferença entre beneficiários e não beneficiários

2 A amostra da PAD/MG é composta por 18 mil domicílios, em 308 municípios de Minas Gerais. A amostra é representativa para os seguintes extratos: zona urbana/rural; Região Metropolitana/Não-metropolitana; Regiões de Planejamento; Belo Horizonte/Demais municípios de Minas Gerais e Mesorregiões de Minas Gerais. Os dados foram coletados entre junho e novembro de 2009. As informações da PAD foram agrupadas em oito seções: características do domicílio, características dos moradores, educação, saúde, trabalho, rendimentos, gastos e juventude. 
do sexo feminino não foram estatisticamente significantes, ao contrário do sexo masculino que apresentou uma diferença entre 3,7\% e 4,3\% a favor dos beneficiários. Não houve diferença estaticamente significante para os que se autodeclararam brancos, entretanto, entre os negros, houve uma diferença entre $3,7 \%$ e $4 \%$.

Uma pesquisa realizada pelo INEP e MEC (2011) através do método "diferenças em diferenças" concluiu que o Bolsa Família elevou a frequência escolar das crianças com idade entre 6 e 16 anos em 3 pontos percentuais, reduzindo em $36 \%$ o número de crianças fora da escola. Os impactos são mais elevados entre os meninos nas áreas urbanas e em meninas nas áreas rurais. No que diz respeito à diferença entre os sexos, os impactos são maiores para o caso dos meninos sendo o programa responsável pela redução de $40 \%$ da proporção de meninos entre 6 e 16 anos que não frequentam a escola contra uma redução de $30 \%$ no que tange ao sexo feminino.

Utilizando dados do censo escolar de 1998 a 2005, Glewwe e Kassouf (2008) constroem um painel onde as mesmas escolas podem ser acompanhadas durante 8 anos, sendo o foco as crianças de $1^{\mathrm{a}}$ a $8^{\mathrm{a}}$ série, e criam também um painel de municípios de 1998 a 2005 contendo dados do Ministério do Desenvolvimento Social sobre a percentagem de famílias que recebem a transferência do Bolsa Família em cada município. Primeiramente, os autores apresentam uma estimativa do impacto do PBF por escola e posteriormente apresentam os resultados por município. $\mathrm{Na}$ análise por escola, os autores chegam à conclusão de que houve um aumento na taxa de matrícula em $5,5 \%$ em escolas de $1^{a}$ a $4^{a}$ série e em $6,5 \%$ em escolas de $5^{a}$ a $8^{a}$ série, diminuição na taxa de abandono de 0,5 pontos percentuais para crianças de $1^{\mathrm{a}}$ a $4^{\mathrm{a}}$ série e 0,4 pontos percentuais para $5^{\mathrm{a}}$ a $8^{\mathrm{a}}$ série. Além disso, os autores reportam um impacto positivo do Bolsa Família no que diz respeito à taxa de aprovação com um efeito de 0,9 pontos percentuais para crianças de $1^{a}$ a $4^{a}$ série e 0,3 pontos percentuais para $5^{a}$ a $8^{a}$ serie. $O$ mesmo pode-se concluir para as estimativas por municípios, entretanto para crianças de $5^{a}$ a $8^{a}$ série os resultados encontrados por município são imprecisos.

Oliveira e Soares (2013), por sua vez, a partir de três fontes de dados individualizadas - o Cadastro Único (CadÚnico), o Censo Escolar e o Projeto Frequência - estimam o efeito do PBF sobre o fluxo escolar para os alunos de primeira a oitava série do ano de 2008. Estes autores utilizaram-se de três abordagens, a primeira estima a probabilidade por meio de regressão logística, usando apenas o universo do CadÚnico; a segunda utilizou, junto ao CadÚnico, a base Projeto de Frequência, no entanto, essa base cobre apenas indivíduos que são beneficiários não sendo possível fazer uma comparação entre beneficiários e não beneficiários; e, na terceira abordagem, ao invés de observar as crianças, observou-se as escolas, utilizando o CadÚnico para estimar a proporção de crianças pobres na escola e O Projeto Presença para identificar aquelas que são beneficiárias do programa. A primeira abordagem mostra que o aluno participante do programa possui uma probabilidade de repetência de $11 \%$ menor que os demais, ao observar a segunda abordagem, apenas entre os beneficiários, não foi possível encontrar indícios de que 
aumentos nas quantias transferidas geram maiores ou menores taxas de repetência, a outra variável considerada, a frequência à escola, indica que os alunos que cumprem as condicionalidades de frequência possuem chances de até 40\% menores de repetência quando comparados àqueles que não cumprem.

Quanto aos possíveis efeitos sobre a qualidade da educação, Camargo (2011) avalia o impacto do PBF sobre o desempenho escolar médio das escolas, utilizando escolas do Brasil inteiro. $\mathrm{O}$ trabalho combina dados do censo escolar 2008 e da prova Brasil 2009 para analisar os possíveis benefícios do recebimento do PBF sobre o desempenho escolar médio dos alunos da quarta série do ensino fundamental. $\mathrm{O}$ autor conclui que escolas com maior nível de beneficiários do PBF obtiveram menor proficiência nos exames de matemática e português, porém essas escolas já apresentavam índices ruins antes de receberem o benefício, o que indica que não necessariamente a queda da nota se deu por conta do aumento do número de beneficiários. Estima-se também uma relação negativa entre a proporção de alunos beneficiados em uma escola e suas taxas de abandono e taxa de aprovação.

Na mesma direção, Pellegrina (2011), com uma rica base de dados, combinando notas dos boletins escolares do período de 2007 a 2009 com as notas do exame SARESP ${ }^{3}$ de 2007 a 2009, avaliou o impacto do PBF sobre a taxa de matrícula e desempenho escolar dos alunos do estado de São Paulo. Utilizando o método de matching (pareamento) e de diferenças-em-diferenças, o autor chegou à conclusão de que o recebimento do beneficio reduz o abandono e aumenta a frequência escolar demonstrando que há um efeito positivo sobre as variáveis atreladas às condicionalidades, no entanto, o impacto é nulo sobre as variáveis de desempenho no boletim e em exames padronizados, o que sugere que o programa não é eficaz no sentido de combater o ciclo de pobreza mantido entre gerações uma vez que não contribui com um impacto positivo na educação dos alunos beneficiários.

Cireno, Silva e Proença (2013), utilizaram dados do CadÚnico, O Sistema Presença, Prova Brasil no ano de 2011 e o Censo escolar de 2011, para analisar a associação entre o PBF e o desempenho e percurso escolar. Primeiro calculou-se as diferenças entre as médias das variáveis para o $5^{\circ}$ e o $9^{\circ}$ ano separadamente e conduziram testes estatísticos da significância da diferença, após isso utilizaram um modelo de mínimos quadrados ordinários (MQO) para as variáveis contínuas, e para as variáveis discretas utilizou-se o modelo probit. Os resultados encontrados revelam que os beneficiários do programa têm, em média, pior desempenho na Prova Brasil que os não beneficiários, no entanto, ao comparar o $5^{\circ}$ e o $9^{\circ}$ ano a "desvantagem" de estar no programa se converte em "vantagem" ao final do ensino fundamental, quanto ao abandono e distorção de séries os beneficiários apresentam menor probabilidade tanto de abandonar a escola quanto de estarem defasados no percurso escolar.

3 Sistema de Avaliação do Rendimento Escolar do Estado de São Paulo. 
No que tange à educação, de forma geral, a condicionalidade do programa contribuiu para a redução da taxa de crianças fora da escola, em todas as idades entre 6 e 16 anos. As taxas de abandono foram menores entre os beneficiários se comparados aos demais alunos da rede pública, assim como também as taxas de aprovação no ensino médio passaram a ser mais favoráveis aos alunos beneficiários, mostrando que o programa vem contribuindo para que a população mais pobre melhore os indicadores relativos à educação (Campello, 2013).

A análise do Gráfico 1 mostra que o programa vem se fortalecendo e expandindo. Hoje já são mais de 13,8 milhões de famílias em todo território nacional participando do programa.

Gráfico 1 | Evolução da cobertura do Bolsa Família - Brasil - 2004/2010

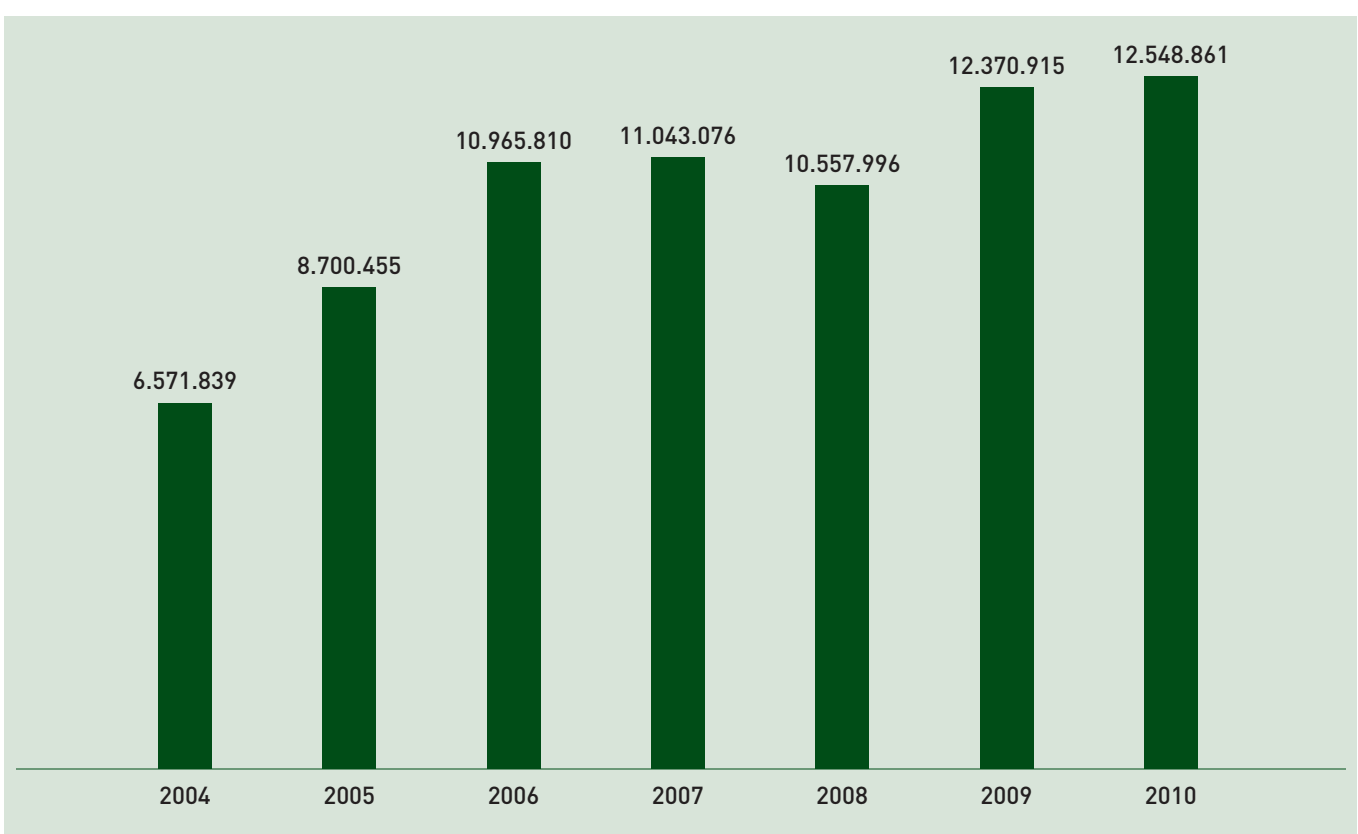

Fonte: Matriz de Informação Social do MDS.

Nota: Valores de 2010 equivalentes ao mês de março.

\section{METODOLOGIA}

\subsection{Base de dados}

Os dados utilizados no trabalho provêm do banco de dados de pessoas e domicílios da Pesquisa Nacional por Amostra Domiciliar (PNAD), do Instituto Brasileiro de Geografia e Estatística (IBGE). Os anos escolhidos foram os anos de 2003, 2004, 2008 e 2012.

A PNAD consiste em uma pesquisa amostral realizada anualmente com o objetivo de investigar, de forma permanente, características gerais da população, de educação, trabalho, rendimento e 
habitação e outras, com periodicidade variável, de acordo com as necessidades de informações para o país, como as características sobre migração, fecundidade, nupcialidade, saúde, segurança alimentar, entre outros temas.

A pesquisa adota um plano amostral estratificado e conglomerado com um, dois ou três estágios de seleção, dependendo do estrato. Isso quer dizer que o desenho amostral da pesquisa não é de uma amostra aleatória simples com reposição. A PNAD é uma amostra nucleada que trabalha com projeção de população independente, uma amostra nucleada estima de forma precisa características de uma população espalhada no território, no entanto pode gerar problemas em casos onde a população é concentrada geograficamente. Em relação à projeção independente, a população que cada PNAD de uma dada década irá projetar é decidida imediatamente após o Censo Demográfico que abre a década. De acordo com os autores Soares et al. (2006), "tanto a amostra como os pesos de cada individuo amostrado são decididos, possivelmente, nove anos antes de uma PNAD ir a campo". Por esse motivo, as grandezas extensivas coletadas pela PNAD, indicativas de quantidade não são muito confiáveis ${ }^{4}$.

Apesar de não responder muito bem as grandezas extensivas, a PNAD não impõem restrições a perguntas relacionadas como grandezas intensivas, ou seja, "a perguntas como, 'Qual é o rendimento médio dos ocupados?' on 'Qual é a renda média dos domicilios recipientes do Bolsa Familia?'” (Soares et al., 2006). Ainda de acordo com o autor, a PNAD pode reproduzir bem em termos relativos à distribuição dos beneficiários e suas características.

\subsubsection{Limitações da base de dados}

A PNAD abrange três tipos de pesquisa: básica (para conhecer a situação socioeconômica do Brasil), suplementar (aprofundamento de temas relevantes no ano da pesquisa) e especial (temas julgados relevantes, mas que não são cobertos pela pesquisa básica). No que tange o suplemento para programas de transferências de renda, temos disponível apenas para o ano de 2004 dentre os anos utilizados na pesquisa. No entanto ainda há limitações quanto ao suplemento da PNAD, pois a pesquisa identifica apenas o domicílio que possui algum membro beneficiário do programa, não contendo informações adicionais como, por exemplo, qual o membro do domicilio é beneficiado nem o valor do beneficio recebido, o que restringe a análise que poderia ser feita com o suplemento.

Outra limitação proveniente dos dados, é que a PNAD é uma pesquisa caracterizadas por dados em cross section, sendo assim, não é possível acompanhar os mesmos indivíduos ao longo do tempo, o que temos são um mesmo conjunto de variáveis coletados em diferentes períodos de tem-

4 “Em outras palavras, a PNAD não responde tão bem perguntas como: 'Quantas pessoas estão empregadas?' ou 'Quantos domicílios recebem Bolsa- Família?”' (Soares et.al, 2006). 
po, em distintas amostras aleatórias de uma mesma população. Entretanto, o agrupamento desses cortes transversais de diferentes anos é eficaz para analisar os efeitos de uma política pública.

Com base no procedimento empregado por Foguel e Barros (2008), identificamos indiretamente os beneficiários do PBF por meio da informação dos valores dos benefícios recebido do programa.

Foguel e Barros (2008) avaliaram os impactos dos programas de transferências condicionais de renda sobre a oferta de trabalho, para os anos de 2001 a 2005. Tal procedimento de identificação dos beneficiários de forma indireta se dá pelo fato da PNAD não reportar a participação dos domicílios em programas sociais, exceto no ano de 2004. Os autores identificam como beneficiário aqueles domicílios que declararam na variável "outros rendimentos” (V1273) combinações exatas de valores típicos transferidos pelos programas.

A tabela 1 apresenta os valores normalmente transferidos por cada programa de transferência condicional de renda utilizado pelos autores.

Tabela 1 - Valores típicos dos benefícios transferidos pelos PTRCs

\begin{tabular}{|l|l|}
\hline Programa & Valor do benefício \\
\hline PETI & 25 (rural), 40 (urbano) \\
\hline Bolsa Escola & $15,30,45$ \\
\hline Bolsa Alimentação & $15,30,45$ \\
\hline Auxílio-Gás & 7,50 \\
\hline Cartão Alimentação & 50 \\
\hline Bolsa Família & $15,30,45,50,65,80,90$
\end{tabular}

Fonte: Barros et al. (2007, Tabela 6).

Os autores pressupõem que "domicílios que derivam renda de ativos financeiros tendem a não ser beneficiários de programas sociais". Partindo dessa hipótese e considerando os valores típicos dos benefícios descritos na tabela acima, identifica-se como beneficiário o domić́lio que declara a combinação exata desses valores na variável "outros rendimentos". Caso o valor declarado não corresponda a um valor típico ele é considerado como "rendimento de ativos financeiros" e o domicílio, não beneficiário.

Selecionamos as famílias consideradas pobres e extremamente pobres de acordo com os valores de corte de pobreza referente a cada um dos anos, e utilizamos o procedimento de "identificação indireta" para selecionar os beneficiários do Bolsa Família, considerados nosso grupo de tratamento. Aquelas pessoas que se situam no mesmo corte de renda determinante da pobreza, mas não declararam na variável "outros rendimentos" o recebimento dos valores específicos do PBF, tomamos como nosso grupo de controle. Supondo assim, que essas pessoas possuem 
todas as características de elegibilidade para participar do programa, no entanto por algum motivo não foram selecionadas, tentando tornar o grupo de controle o mais próximo possível do grupo de tratamento.

Utilizamos os dados do ano de 2003, com o objetivo de observamos as famílias antes e depois da implementação do programa. Assim realizamos a correção monetária sobre os valores dos benefícios e corte de renda do primeiro ano do programa, em 2004, a fim de construirmos os mesmo grupos para o ano de 2003.

A tabela 2 sumariza a evolução dos critérios de elegibilidade e dos valores dos benefícios ao longo dos anos usados neste trabalho para a construção dos grupos de tratamento e controle.

\section{Tabela 2 | Critério de elegibilidade e valor dos benefícios de 2003 a 2012}

\begin{tabular}{|c|c|c|c|c|}
\hline \multirow[b]{2}{*}{ Situação Familiar } & \multicolumn{4}{|c|}{ Critério de elegibilidade } \\
\hline & 2003 & 2004 & 2008 & 2012 \\
\hline Extremamente pobres & 47,14 & 50,00 & 60,00 & 70,00 \\
\hline \multirow[t]{2}{*}{ Pobres } & 47,15 a 94,28 & 50,01 a 100,00 & 60,01 a 120,00 & 70,01 a 140,00 \\
\hline & \multicolumn{4}{|c|}{ Valor do Benefício } \\
\hline Benefício & 2003 & 2004 & 2008 & 2012 \\
\hline Básico & 47,00 & 50,00 & 62,00 & 70,00 \\
\hline Variável* & 13,00 & 15,00 & 20,00 & 32,00 \\
\hline Variável Adolescente** & - & - & 30,00 & 38,00 \\
\hline
\end{tabular}

Fonte: Elaboração própria com informações da legislação do PBF.

* Em Junho de 2011 o limite mudou de 3 para 5 benefícios por família.

** Limite de 2 benefícios por família.

O benefício básico é concedido às famílias "extremamente pobres” independente da composição familiar, podendo essas famílias acumular o benefício básico junto ao benefício variável repassado as famílias pobres que tenham crianças e adolescentes de até 15 anos, com um teto de até três benefícios variáveis por família. No biênio 2007/2008, foi criado o benefício variável vinculado ao adolescente (BVJ), pago às famílias com membros com idade entre 16 e 17 anos, com um limite de até dois benefícios por família. Em junho de 2011 o limite do benefício variável passou de três para cinco benefícios por família, com crianças e adolescentes até 15 anos.

Compreendendo que em 2003 ainda não havia o programa, consideramos o maior valor do benefício correspondente no ano de 2004, corrigido para 2003.

Assim, filtramos da variável "outros rendimentos” os possíveis valores dos benefícios em cada ano, considerando beneficiárias as famílias que declararam alguma combinação exata desses valores, como reportados na tabela 3. 


\begin{tabular}{|l|l|}
\hline Ano & Valores dos benefícios \\
\hline 2003 & Consideramos valores menores ou iguais 87,00 \\
\hline 2004 & $15,30,45,50,65,80,95$ \\
\hline 2008 & $62,82,102,122,92,00,112,132,152,142,162,182,20,40,60$, \\
\hline 2012 & $30,70,90,80,100,120$ \\
\hline & $70,102,134,166,198,230,108,140,172,204,236,268,146$, \\
\hline
\end{tabular}

Fonte: Elaboração própria com informações da legislação do PBF.

\subsection{Modelo econométrico}

No caso do programa Bolsa Família não foi possível implementar uma avaliação experimental do programa por vários motivos, entre eles estão, o fato do programa ter sido criado a partir de migração e integração de vários outros programas já existentes, e também o problema ético de criar um grupo de controle aleatório que acarretaria na negação do benefício a um determinado número de famílias, o que iria contra a proposta do programa uma vez que o Governo Federal havia estabelecido a universalização do programa entre o público alvo (as famílias consideradas extremamente pobres e aquelas situadas na linha de pobreza) até o final do primeiro mandato do presidente Luiz Inácio Lula da Silva.

Diante da impossibilidade de se trabalhar com um método experimental, adotaremos uma metodologia quase experimental, que consiste na comparação das famílias beneficiárias com outras que não recebem o benefício, mas que apresentam características socioeconômicas semelhantes.

Para as finalidades desse artigo, será utilizado o método conhecido como diferenças em diferenças (DD). Tal método será empregado para avaliar os efeitos das transferências de renda do programa Bolsa Família sobre a escolaridade dos residentes com idade entre 15 e 25 anos nos domicílios beneficiados. A condição do recebimento do benefício é famílias com crianças até 17 anos, porém dado que o benefício é somado a renda familiar como um todo, o objetivo é analisar se este aumento na renda surte efeito também sobre os jovens e adultos incluídos no grupo familiar.

O grupo de controle é emparelhado ao grupo de tratamento por meio de uma série de características observáveis. A hipótese principal do modelo conhecida como seleção nos observáveis, estabelece que condicional ao vetor de variáveis $\mathrm{X}$, não pode existir nenhuma outra variável não observável que influencie simultaneamente a decisão de participar ou não no tratamento e nos resultados potenciais, ou seja, as variáveis observáveis utilizadas devem ser suficientes para, uma vez controladas, tornar a participação no programa Bolsa Família um evento aleatório. 
O modelo consiste em uma dupla subtração: primeiro calculamos a diferença das médias da variável de resultado entre os períodos anterior e posterior ao programa, para o grupo de tratamento e para o grupo de controle, feito isso passamos a segunda diferença que consiste no cálculo da diferença da primeira diferença calculada para os dois grupos. A utilização de tal método requer que tenhamos informações para ambos os grupos para pelo menos um período de tempo antes e um período de tempo depois do programa, nesse caso adotamos o ano de 2003 como referência para o período antes da execução do programa e os anos de 2004, 2008 e 2012 como posteriores a implementação do Bolsa Família.

A principal hipótese do método DD é que a trajetória temporal da variável de resultado para o grupo de controle represente o que ocorreria com o grupo tratado caso não houvessem recebido o benefício. Em outras palavras, queremos criar um "clone" para quem recebeu o beneficio da intervenção da política (no caso o Programa Bolsa Família), e através da diferença no resultado de interesse entre o beneficiário e um indivíduo igual ao beneficiário que, no mesmo período, não recebeu o benefício, observar o impacto ocorrido nesses indivíduos. Para isto utilizamos dois grupos onde no primeiro momento - no nosso caso o ano de 2003 - nenhum dos dois grupos é exposto ao tratamento, já no segundo período apenas um deles é exposto ao tratamento que chamamos de tratados, enquanto o grupo de controle permanece isolado ao tratamento.

A ideia é um grupo de controle que se pareça ao máximo com o grupo de tratados, e que estejam sujeitos às mesmas influências dos fatores que afetam a variável de resultado dos tratados, no nosso caso, por exemplo, que estejam sujeitos às mesmas condições socioeconômicas, tenha o mesmo background familiar, convivam em ambientes familiares com características parecidas, disponham da mesma qualidade da infraestrutura da escola. Obviamente, não há garantias de que a única diferença entre os dois grupo seja a participação no programa, mas o método DD, assim como os demais métodos experimentais, busca minimizar os erros decorrentes da seleção.

Expressamos o estimador do método de diferenças em diferenças calculando uma dupla diferença de médias da variável de resultado. Denotamos por $T=\{1,0\}$ a participação ou não no programa e por $\mathrm{t}=\{1,0\}$ os períodos posteriores e anteriores a implementação do PBF, logo, o estimador de DD será dado por:

(1) $\beta d d=\{E[Y \mid T=1, t=1]-E[Y \mid T=1, t=0]\}-\{E[Y \mid T=0, t=1]-[E[Y \mid T=0, t=0]\}$,

ou seja, calculamos a diferença temporal do que ocorreu com o grupo de tratamento subtraída da mesma diferença calculada para o grupo de controle. Embutida neste estimador a hipótese de que a variação temporal na variável de resultado para o grupo de controle representa a variação contrafactual do grupo tratado,

$E[Y(0) \mid T=1, t=0]-[E[Y(0) \mid T=1, t=0]=[Y(0) \mid T=0, t=1]-E[Y(0) \mid T=0, t=0]$ 
Isto é, a variação que seria experimentada pelo grupo de tratamento na ausência da participação no PBF. A diferença entre a variação efetivamente observada para o grupo de tratamento e a variação contrafactual fornecida pelo grupo de controle vai capturar o efeito causal da política pública.

Uma forma equivalente de expressar o estimador de DD é através da dupla diferença:

$(2) \beta d d=\{E[Y \mid T=1, t=1]-E[Y \mid T=0, t=1]\}-\{E[Y \mid T=1, t=0]-E[Y \mid T=0, t=0]\}$

Que é apenas o rearranjo da expressão (1). A expressão (2) mostra que o estimador de DD também pode ser visto como a diferença das médias da variável de resultado entre os dois grupos no período anterior e posterior ao programa.

Aplicaremos este método utilizando dados da PNAD para os anos de 2003, 2004, 2008, 2012 a fim de observar o impacto do PBF sobre a escolaridade dos jovens das famílias beneficiadas.

\subsection{ESTATÍSTICAS DESCRITIVAS}

As variáveis que determinam a participação no programa Bolsa Família provêm das características familiares, neste sentido, selecionamos algumas variáveis que indicam as condições socioeconômicas, características dos indivíduos, e características do chefe do domicílio.

As variáveis de resposta se desdobram em três categorias: (i) anos de escolaridade dos jovens; (ii) frequência à escola; (iii) nível de aprovação. Tais variáveis se destinam a captar o impacto do programa sob o prisma da educação entre os jovens das famílias beneficiadas. Os impactos do Programa Bolsa Família sobre essas variáveis foram investigados a partir do recorte de jovens com idade entre 15 e 25 anos.

Dessa forma, foram utilizadas além das três variáveis de resultado, vinte e quatro variáveis independentes, divididas em dois blocos: características do chefe do domicílio e características familiares e do domicílio. Como descrito na tabela. 
Tabela 4 | Descrição das variáveis

\begin{tabular}{|c|c|}
\hline Variáveis dependentes & Descrição \\
\hline Escolaridade & A variável está definida em anos, variando de 0 a 15 anos de estudo. \\
\hline Frequenta escola & $\begin{array}{l}\text { A variável dummy é igual a } 1 \text { se sim, igual a } 0 \text { caso a pessoa não } \\
\text { frequente a escola. }\end{array}$ \\
\hline Foi aprovado & $\begin{array}{l}\text { A variável dummy é igual a } 1 \text { se sim, igual a } 0 \text { caso a pessoa não } \\
\text { tenha concluído a série anterior com aprovação. }\end{array}$ \\
\hline Variáveis independentes & Descrição \\
\hline \multicolumn{2}{|c|}{ Características do chefe do domicílio } \\
\hline Gênero & $\begin{array}{l}\text { A variável dummy é igual a } 1 \text { caso o chefe seja do sexo masculino, } \\
\text { e igual a } 0 \text { para o sexo feminino. }\end{array}$ \\
\hline Raça & $\begin{array}{l}\text { A variável dummy é igual a } 1 \text { caso o chefe se declare branco, e } 0 \\
\text { se não branco. }\end{array}$ \\
\hline Sabe ler e escrever & A variável dummy é igual a 1 se sim, e igual a 0 se não. \\
\hline Trabalha & $\begin{array}{l}\text { A variável dummy é igual a } 1 \text { caso o individuo esteja trabalhando } \\
\text { na semana de referencia, e igual a } 0 \text { caso não. }\end{array}$ \\
\hline Idade que começou a trabalhar & A variável está definida em anos, variando de 4 a 80 anos. \\
\hline Escolaridade & A variável está definida em anos, variando de 0 a 15 anos de estudo. \\
\hline \multicolumn{2}{|c|}{ Características Familiares e do domicílio } \\
\hline Área & $\begin{array}{l}\text { A variável dummy é igual a } 1 \text { se reside em área urbana, } \\
\text { e igual a } 0 \text { caso resida em área rural. }\end{array}$ \\
\hline Casa própria & $\begin{array}{l}\text { A variável dummy é igual a } 1 \text { se possui casa própria, } \\
\text { igual a } 0 \text { se não. }\end{array}$ \\
\hline Saneamento básico & $\begin{array}{l}\text { A variável dummy é igual a } 1 \text { se o domicilio tem saneamento } \\
\text { básico, igual a } 0 \text { se não. }\end{array}$ \\
\hline Destino do lixo & $\begin{array}{l}\text { A variável dummy é igual a } 1 \text { se o domicilio tem lixo é coletado } \\
\text { diretamente, igual a } 0 \text { se não. }\end{array}$ \\
\hline Tem energia elétrica & $\begin{array}{l}\text { A variável dummy é igual a } 1 \text { se o domicilio tem energia elétrica, } \\
\text { igual a } 0 \text { se não. }\end{array}$ \\
\hline Tem banheiro & $\begin{array}{l}\text { A variável dummy é igual a } 1 \text { se o domicilio tem banheiro, igual a } \\
0 \text { se não. }\end{array}$ \\
\hline Água canalizada & $\begin{array}{l}\text { A variável dummy é igual a } 1 \text { se o domicilio tem água canalizada, } \\
\text { igual a } 0 \text { se não. }\end{array}$ \\
\hline Número de Cômodos & A variável inclui todos os cômodos do domicilio e varia de 1 a 30 . \\
\hline Geladeira & A variável dummy é igual a 1 se tem geladeira, igual a 0 se não. \\
\hline Máquina de lavar roupa & $\begin{array}{l}\text { A variável dummy é igual a } 1 \text { se tem máquina de lavar roupa, } \\
\text { igual a } 0 \text { se não. }\end{array}$ \\
\hline Microcomputador & $\begin{array}{l}\text { A variável dummy é igual a } 1 \text { se tem microcomputador, } \\
\text { igual a } 0 \text { se não. }\end{array}$ \\
\hline Tem mãe viva & A variável dummy é igual a 1 se a mãe for viva, igual a 0 se não. \\
\hline Mãe mora no domicílio & $\begin{array}{l}\text { A variável dummy é igual a } 1 \text { se a mãe residir no domicílio, } \\
\text { igual a } 0 \text { se não. }\end{array}$ \\
\hline Rendimento mensal familiar & A variável está definida em reais, no valor do ano corrente. \\
\hline Moradores de 6 a 17 anos & $\begin{array}{l}\text { O motivo para este recorte está no critério de condicionalidades } \\
\text { na área da educação. }\end{array}$ \\
\hline Escolaridade & A variável está definida em anos, variando de 0 a 15 anos de estudo. \\
\hline Frequenta escola & $\begin{array}{l}\text { A variável dummy é igual a } 1 \text { se sim, igual a } 0 \text { caso a pessoa não } \\
\text { frequente a escola. }\end{array}$ \\
\hline Rede de ensino & $\begin{array}{l}\text { A variável dummy é igual a } 1 \text { para a rede de ensino pública, igual a } \\
0 \text { para a rede de ensino particular. }\end{array}$ \\
\hline
\end{tabular}


As tabelas abaixo mostram uma análise comparativa das características observáveis entre beneficiários e não beneficiários ao longo dos anos.

Tabela 5 | Estatísticas descritivas das variáveis utilizadas

\begin{tabular}{|c|c|c|c|c|c|}
\hline \multirow{2}{*}{$\begin{array}{l}\text { Variáveis independentes } \\
\text { Características do chefe do domicílio }\end{array}$} & \multicolumn{5}{|c|}{2003} \\
\hline & Controle & Tratamento & Diferença & Pvalor & \\
\hline Gênero & .7113726 & .8118658 & .1004932 & 0.000 & ${ }^{* * *}$ \\
\hline Raça & .3334871 & .3471128 & .0136257 & 0.116 & \\
\hline Sabe ler e escrever & .7550851 & .6781803 & -.0769049 & 0.000 & *** \\
\hline Trabalha & .6478824 & .810087 & .1622046 & 0.000 & *** \\
\hline Idade que começou a trabalhar & 12.395 & 11.44752 & -.9474743 & 0.000 & ${ }^{* * *}$ \\
\hline Escolaridade & 4.109483 & 3.549143 & -.56034 & 0.000 & *** \\
\hline \multicolumn{6}{|l|}{ Características Familiares e do domicílio } \\
\hline Área & .9504629 & .9524495 & .0019865 & 0.677 & \\
\hline Casa própria & .6953489 & .7532454 & .0578965 & 0.000 & *** \\
\hline Saneamento básico & .3478028 & .2858166 & -.0619863 & 0.000 & *** \\
\hline Lixo coletado diretamente & .6281559 & .5589314 & -.0692246 & 0.000 & *** \\
\hline Tem energia elétrica & .9260263 & .9110545 & -.0149717 & 0.017 & ** \\
\hline Tem banheiro & .8504307 & .8230996 & -.0273311 & 0.006 & $* * *$ \\
\hline Água canalizada & .2612967 & .2507876 & -.0105091 & 0.571 & \\
\hline Número de Cômodos & 4.986591 & 5.587543 & .6009515 & 0.000 & *** \\
\hline Geladeira & .7006631 & .672051 & -.0286121 & 0.005 & *** \\
\hline Máquina de lavar roupa & .1155645 & .1118839 & -.0036806 & 0.531 & \\
\hline Microcomputador & .0189783 & .0440186 & .0250403 & 0.000 & *** \\
\hline Tem mãe viva & .8635454 & .8425679 & -.0209775 & 0.000 & $* * *$ \\
\hline Mãe mora no domicílio & .6550565 & .6565144 & .0014579 & 0.652 & \\
\hline Rendimento mensal familiar & 232.0899 & 647.701 & 415.6111 & 0.000 & *** \\
\hline Moradores de 6 a 17 anos & .3199419 & .4111684 & .0912266 & 0.000 & *** \\
\hline Escolaridade & .176659 & 3.587893 & .4112348 & 0.000 & $* * *$ \\
\hline Frequenta escola & .3517256 & .4569279 & .1052023 & 0.000 & *** \\
\hline \multirow[t]{2}{*}{ Rede de ensino } & 9441284 & .9553792 & .0112508 & 0.000 & *** \\
\hline & \multicolumn{5}{|c|}{2004} \\
\hline Características do chefe do domicílio & Controle & Tratamento & Diferença & Pvalor & \\
\hline Gênero & .7116883 & .7946706 & .0829822 & 0.000 & *** \\
\hline Raça & .3222505 & .3221158 & -.0001346 & 0.986 & \\
\hline Sabe ler e escrever & .739799 & .6891714 & -.0506276 & 0.000 & *** \\
\hline Trabalha & .6885815 & .8011018 & .1125203 & 0.000 & *** \\
\hline Idade que começou a trabalhar & 12.27611 & 1164672 & -.6293859 & 0.000 & $* * *$ \\
\hline Escolaridade & 4.089217 & 3.466082 & -.6231355 & 0.000 & *** \\
\hline \multicolumn{6}{|l|}{ Características Familiares e do domicílio } \\
\hline Área & .9457726 & .9462264 & .0004539 & 0.929 & \\
\hline Casa própria & .7048461 & .7438954 & .0390493 & 0.000 & $* * *$ \\
\hline Saneamento básico & .328971 & .2826721 & -.0462989 & 0.000 & $* * *$ \\
\hline Lixo coletado diretamente & .5763524 & .5435072 & -.0328453 & 0.005 & *** \\
\hline
\end{tabular}




\begin{tabular}{|c|c|c|c|c|c|}
\hline Tem energia elétrica & .905573 & .9154587 & .0098856 & 0.180 & \\
\hline Tem banheiro & .8409872 & .8280513 & -.0129359 & 0.158 & \\
\hline Água canalizada & .2325412 & .2449081 & .0123669 & 0.452 & \\
\hline Número de Cômodos & 4.984854 & 5.278785 & .2939308 & 0.000 & $* * *$ \\
\hline Geladeira & .6689797 & .6823671 & .0133873 & 0.213 & \\
\hline Máquina de lavar roupa & .0957895 & .0759384 & -.0198511 & 0.000 & *** \\
\hline Microcomputador & .0175677 & .0195112 & .0019435 & 0.334 & \\
\hline Tem mãe viva & .867381 & -.0165978 & -.0165978 & 0.000 & $* * *$ \\
\hline Mãe mora no domicílio & .6545624 & .6635815 & .0090191 & 0.009 & $* * *$ \\
\hline Rendimento mensal familiar & 258.5766 & 585.8062 & 3272296 & 0.000 & $* * *$ \\
\hline Moradores de 6 a 17 anos & .337645 & .4119845 & .0743395 & 0.000 & $* * *$ \\
\hline Escolaridade & 3.189873 & 3.415239 & .2253663 & 0.000 & *** \\
\hline Frequenta escola & .365618 & .4539978 & .0883797 & 0.000 & $* * *$ \\
\hline \multirow[t]{2}{*}{ Rede de ensino } & .9458951 & .9666085 & .0207134 & 0.000 & *** \\
\hline & \multicolumn{5}{|c|}{2008} \\
\hline Características do chefe do domicílio & Controle & Tratamento & Diferença & Pvalor & \\
\hline Gênero & .6195993 & .7088203 & .089221 & 0.000 & *** \\
\hline Raça & .2941974 & .2869277 & -.0072697 & 0.284 & \\
\hline Sabe ler e escrever & .7975696 & .7270823 & -.0704873 & 0.000 & $* * *$ \\
\hline Trabalha & .5740092 & .7700796 & .1960704 & 0.000 & *** \\
\hline Idade que começou a trabalhar & 12.70442 & 11.99961 & -.7048104 & 0.000 & *** \\
\hline Escolaridade & 4.973351 & 4.06832 & -.9050315 & 0.000 & $* * *$ \\
\hline \multicolumn{6}{|l|}{ Características Familiares e do domicílio } \\
\hline Área & .9462093 & .9409504 & -.0052589 & 0.231 & \\
\hline Casa própria & .7013001 & .7405347 & .0392346 & 0.000 & $* * *$ \\
\hline Saneamento básico & .3683511 & .3043804 & -.0639707 & 0.000 & *** \\
\hline Lixo coletado diretamente & .6387083 & .5962817 & -.0424266 & 0.000 & $* * *$ \\
\hline Tem energia elétrica & .9520688 & .9540619 & .0019931 & 0.595 & \\
\hline Tem banheiro & .8799426 & .8691086 & -.010834 & 0.122 & \\
\hline Água canalizada & .2154686 & .2079942 & -.0074744 & 0.616 & \\
\hline Número de Cômodos & 5.086284 & 5.309899 & .223615 & 0.000 & $* * *$ \\
\hline Geladeira & .7462132 & .7775709 & .0313577 & 0.000 & $* * *$ \\
\hline Máquina de lavar roupa & .1651112 & .1290467 & -.0360645 & 0.000 & $* * *$ \\
\hline Microcomputador & .0837494 & .0729468 & -.0108025 & 0.012 & $* *$ \\
\hline Tem mãe viva & .8670854 & .8487326 & -.0183528 & 0.000 & $* * *$ \\
\hline Mãe mora no domicílio & .6350738 & .6452296 & .0101558 & 0.009 & $* * *$ \\
\hline Rendimento mensal familiar & 294.6243 & 875.8409 & 581.2166 & 0.000 & $* * *$ \\
\hline Moradores de 6 a 17 anos & .3222621 & .392037 & .0697749 & 0.000 & $* * *$ \\
\hline Escolaridade & 3.673486 & 3.851027 & .1775405 & 0.000 & $* * *$ \\
\hline Frequenta escola & .3541787 & .441031 & .0868523 & 0.000 & $* * *$ \\
\hline \multirow[t]{2}{*}{ Rede de ensino } & .9438332 & .9656186 & .0217854 & 0.000 & $* * *$ \\
\hline & \multicolumn{5}{|c|}{2012} \\
\hline Características do chefe do domicílio & Controle & Tratamento & Diferença & Pvalor & \\
\hline Gênero & .5731578 & .6394111 & .0662532 & 0.000 & *** \\
\hline Raça & .2603374 & .2562504 & -.0040869 & 0.604 & \\
\hline
\end{tabular}




\begin{tabular}{|c|c|c|c|c|c|}
\hline Sabe ler e escrever & .7803442 & .7939661 & .0136219 & 0.127 & \\
\hline Trabalha & .468289 & .7162 & .247911 & 0.000 & $* * *$ \\
\hline Idade que começou a trabalhar & 12.78331 & 12.93495 & .1516365 & 0.129 & \\
\hline Escolaridade & 5.140525 & 4.935636 & -.2048888 & 0.017 & ** \\
\hline \multicolumn{6}{|c|}{ Características Familiares e do domicílio } \\
\hline Área & .9015652 & .9126022 & .0110369 & 0.113 & \\
\hline Casa própria & .7272697 & .7168183 & -.0104514 & 0.246 & \\
\hline Saneamento básico & .3609044 & .3276271 & -.0332772 & 0.002 & *** \\
\hline Lixo coletado diretamente & .5891523 & .6611907 & .0720384 & 0.000 & *** \\
\hline Tem energia elétrica & .9717896 & .9899684 & .0181788 & 0.000 & $* * *$ \\
\hline Tem banheiro & .856571 & .9308906 & .0743196 & 0.000 & $* * *$ \\
\hline Água canalizada & .1855962 & .1941761 & .0085799 & 0.664 & \\
\hline Número de Cômodos & 5.063259 & 5.330201 & .2669413 & 0.000 & $* * *$ \\
\hline Geladeira & .8381217 & .9230726 & .0849509 & 0.000 & $* * *$ \\
\hline Máquina de lavar roupa & .2417899 & .2337981 & -.0079918 & 0.330 & \\
\hline Microcomputador & .1667811 & .2100467 & .0432657 & 0.000 & $* * *$ \\
\hline Tem mãe viva & .8667604 & .8380631 & -.0286973 & 0.000 & $* * *$ \\
\hline Mãe mora no domicílio & .6396752 & .596523 & -.0431522 & 0.000 & $* * *$ \\
\hline Rendimento mensal familiar & 333.0196 & 1145.346 & 8123267 & 0.000 & $* * *$ \\
\hline Moradores de 6 a 17 anos & .3455969 & .337478 & -.0081189 & 0.070 & * \\
\hline Escolaridade & 3.896444 & 4.462451 & .5660069 & 0.000 & $* * *$ \\
\hline Frequenta escola & .3849189 & .3865956 & .0016768 & 0.720 & \\
\hline Rede de ensino & .9381879 & .9407861 & .0025982 & 0.535 & \\
\hline
\end{tabular}

Fonte: Elaboração própria com base nos microdados da PNAD de 2003, 2004, 2008 e 2012.

A análise do perfil do responsável familiar mostra que, em relação ao grupo de não tratados, os beneficiários apresentam um maior número de famílias chefiadas por indivíduos do sexo masculino. No que diz respeito à raça, a diferença entre beneficiários e não beneficiários não é significativa, sendo ambos os grupos em sua maioria não brancos. Quanto à condição de trabalho, o grupo de tratamento apresenta um maior número de chefes economicamente ativos, tendo estes ingressados mais cedo no mercado de trabalho. Verifica-se também um baixo nível de escolaridade, sendo menor entre os chefes de famílias dos domicílios beneficiários o que justifica o maior índice de analfabetismo.

Há uma maior concentração de famílias vivendo em áreas urbanas tanto no grupo de tratados como não tratados. Dentre as variáveis de características de infraestrutura do domicílio, as famílias beneficiadas possuem casa própria com água canalizada e energia elétrica, mas não possuem saneamento básico.

Dado o incremento do benefício, a renda do grupo de tratamento é maior quando comparada ao grupo de não tratados, estes domicílios também apresentam maior número de crianças e adolescentes entre 6 e 17 anos, faixa elegível para o recebimento do benefício, com exceção do ano de 2012. 
As variáveis de escolaridade incluindo todos os moradores indicam maiores anos de estudos para os moradores das famílias beneficiadas, com maior taxa de matrícula na rede pública de ensino, no entanto, quando se observa a frequência escolar esta é maior e significativa para o grupo de tratamento até o ano de 2008, em 2012 esta variável passa a não ser mais significativa entre os grupos. Diante da expansão recente do acesso escolar, tais evidências não são de fácil interpretação.

Quando olhamos para as variáveis de resultados do grupo de interesse - jovens e adultos de 15 a 25 anos - os anos de estudo e a frequência escolar são ambos maiores e estatisticamente significantes para o grupo de beneficiários do PBF. A variável de aprovação que indica se o indivíduo concluiu com aprovação o curso que frequentou anteriormente, não foi significativa apenas para o ano de 2003.

Tabela 6 | Estatísticas descritivas para as variáveis de resultado

\begin{tabular}{|c|c|c|c|c|c|}
\hline \multirow[t]{2}{*}{ Variáveis de Resultado } & \multicolumn{5}{|c|}{2003} \\
\hline & Controle & Tratamento & Diferença & Pvalor & \\
\hline Escolaridade & 6.063456 & 6.309286 & .2458306 & 0.000 & $* * *$ \\
\hline Frequenta escola & .3697635 & .5674949 & .1977315 & 0.000 & $* * *$ \\
\hline \multirow[t]{3}{*}{ Foi aprovado } & .9493353 & .9461831 & -.0031522 & 0.480 & \\
\hline & \multicolumn{5}{|c|}{2004} \\
\hline & Controle & Tratamento & Diferença & Pvalor & \\
\hline Escolaridade & 6.123925 & 6.290814 & .1668889 & 0.007 & $* * *$ \\
\hline Frequenta escola & .3643699 & .5317744 & .1674045 & 0.000 & $* * *$ \\
\hline \multirow[t]{3}{*}{ Foi aprovado } & .9529556 & .9607358 & .0077803 & 0.081 & $*$ \\
\hline & \multicolumn{5}{|c|}{2008} \\
\hline & Controle & Tratamento & Diferença & Pvalor & \\
\hline Escolaridade & 6.900499 & 7.079094 & .1785951 & 0.002 & $* * *$ \\
\hline Frequenta escola & .346522 & .5146112 & .1680892 & 0.000 & $* * *$ \\
\hline \multirow[t]{3}{*}{ Foi aprovado } & .9429027 & .9512243 & .0083215 & 0.096 & $*$ \\
\hline & \multicolumn{5}{|c|}{2012} \\
\hline & Controle & Tratamento & Diferença & Pvalor & \\
\hline Escolaridade & 7.325726 & 7.724792 & 3990661 & 0.000 & $* * *$ \\
\hline Frequenta escola & .3925823 & .4726056 & .0800234 & 0.000 & $* * *$ \\
\hline Foi aprovado & .9430166 & .953644 & .0106274 & 0.087 & * \\
\hline
\end{tabular}

Fonte: Elaboração própria com base nos microdados da PNAD de 2003, 2004, 2008 e 2012.

\section{ANÁLISE DOS RESULTADOS}

Os resultados obtidos a partir do modelo de diferenças em diferenças, para os três anos analisados, encontram-se na tabela 7. As variáveis utilizadas no modelo foram definidas através de várias tentativas para se alcançar o melhor ajuste possível. Assim incluímos na primeira regressão a dummy de ano e a participação ou não no PBF, depois realizamos o mesmo procedimento 
levando em consideração características demográficas e características familiares, e por último acrescentamos ao modelo características do domicílio.

Tabela 7 | Impactos do Bolsa Família sobre os jovens entre 15 e 25 anos de idade

\begin{tabular}{|c|c|c|c|c|c|c|c|c|c|}
\hline \multirow[t]{2}{*}{ VARIÁVEL } & \multicolumn{3}{|c|}{ Escolaridade } & \multicolumn{3}{|c|}{ Foi aprovado } & \multicolumn{3}{|c|}{ Frequenta escola } \\
\hline & (1) & (2) & (3) & (1) & (2) & (3) & (1) & (2) & (3) \\
\hline \multirow[t]{2}{*}{$\begin{array}{l}\text { Beneficiários*A- } \\
\text { no } 2004\end{array}$} & -0.079 & -0.040 & 0.154 & $0.011^{*}$ & $0.012^{*}$ & 0.010 & $-0.030^{* * *}$ & $-0.017^{*}$ & -0.016 \\
\hline & $(0.093)$ & $(0.071)$ & $(0.165)$ & $(0.006)$ & $(0.007)$ & (0.015) & $(0.012)$ & $(0.009)$ & $(0.026)$ \\
\hline \multirow{2}{*}{$\begin{array}{l}\text { Beneficiários* } \\
\text { Ano } 2008\end{array}$} & -0.067 & 0.048 & $0.340^{* *}$ & $0.011^{*}$ & $0.014^{*}$ & 0.032 & $-0.030^{* *}$ & -0.007 & -0.023 \\
\hline & $(0.090)$ & $(0.070)$ & $(0.159)$ & $(0.007)$ & $(0.007)$ & $(0.020)$ & $(0.013)$ & $(0.009)$ & $(0.026)$ \\
\hline \multirow[t]{2}{*}{$\begin{array}{l}\text { Beneficiários* } \\
\text { Ano } 2012\end{array}$} & 0.153 & $0.232^{* * *}$ & 0.259 & $0.014^{*}$ & $0.015^{*}$ & 0.007 & $-0.118^{* * *}$ & $-0.042^{* * *}$ & -0.051 \\
\hline & $(0.107)$ & $(0.084)$ & $(0.217)$ & (0.008) & $(0.008)$ & $(0.021)$ & $(0.015)$ & $(0.012)$ & $(0.032)$ \\
\hline \multirow[t]{2}{*}{ Beneficiários } & $0.246^{* * *}$ & $0.449 * * *$ & $0.248^{* *}$ & -0.003 & 0.002 & 0.004 & $0.198^{* * *}$ & $0.093^{* * *}$ & $0.075^{* * *}$ \\
\hline & $(0.076)$ & $(0.057)$ & $(0.124)$ & $(0.005)$ & $(0.005)$ & $(0.011)$ & $(0.009)$ & $(0.007)$ & $(0.018)$ \\
\hline \multirow[t]{2}{*}{ Constante } & $6.063^{* * *}$ & $2.025^{* * *}$ & $4.514^{* * *}$ & $0.949 * * *$ & $0.911^{* * *}$ & $0.980 * * *$ & $0.370^{* * *}$ & $1.723^{* * *}$ & $1.064^{* * *}$ \\
\hline & (0.089) & $(0.112)$ & $(0.398)$ & $(0.003)$ & $(0.011)$ & $(0.041)$ & $(0.007)$ & $(0.017)$ & $(0.062)$ \\
\hline Dummies de Ano & Sim & Sim & Sim & Sim & Sim & Sim & Sim & Sim & Sim \\
\hline $\begin{array}{l}\text { Características } \\
\text { Demográficas }\end{array}$ & Não & Sim & Sim & Não & Sim & Sim & Não & Sim & Sim \\
\hline $\begin{array}{l}\text { Características } \\
\text { Familiares }\end{array}$ & Não & Sim & Sim & Não & Sim & Sim & Não & Sim & Sim \\
\hline $\begin{array}{l}\text { Características } \\
\text { Domiciliares }\end{array}$ & Não & Não & Sim & Não & Não & Sim & Não & Não & Sim \\
\hline Observações & 85810 & 81885 & 11307 & 45220 & 42630 & 6033 & 86623 & 82490 & 11410 \\
\hline $\mathrm{R}^{2}$ & 0.04 & 0.26 & 0.22 & 0.00 & 0.01 & 0.02 & 0.03 & 0.34 & 0.34 \\
\hline
\end{tabular}

Fonte: PNAD/ IBGE - pesquisa domiciliar.

Nota: o conjunto de controles para características familiares e do chefe do domicílio é composto por: gênero, raça, idade, se o individuo trabalha, se tem mãe viva, se a mãe mora no domicílio; o conjunto de variáveis para o chefe de família inclui sexo, raça, escolaridade, e se trabalha. O conjunto com características do domicilio é composto por: água canalizada, banheiro, energia elétrica, saneamento básico, área, moradores de 6 a 17 anos, geladeira, máquina de lavar roupa e microcomputador.

Erros padrão robusto entre parênteses - * significante a $10 \%$; ** significante a $5 \%$; *** significante a $1 \%$.

Analisando os preditores inicialmente para o grupo de jovens e adultos entre 15 e 25 anos, não obtemos indícios de aumento na escolaridade para esses indivíduos pelo simples fato de residirem em domicílios beneficiados. Quando controlamos pelas características demográficas e familiares a variável de escolaridade passa a ser significativa para o ano de 2012, e ao incluir as características domiciliares esta variável passa a ser estatisticamente significante apenas para o ano de 2008, com um ganho de 0,4 anos a mais de estudos para os beneficiários. Quanto a variável de aprovação os resultados são positivos e estatisticamente significantes a $10 \%$ para o grupo de beneficiários, a probabilidade de esses jovens terem sido aprovados é de 1,4\% maior quando comparados ao grupo de não beneficiários. No entanto, a variável de frequência escolar, controlando pelas variáveis observáveis aparece como negativa e significativa para este grupo, pertencer a um domicilio beneficiário reduz em 11,4\% a probabilidade de esses jovens 
frequentarem a escola. Esse resultado pode ser avaliado a luz do custo de se manter na escola que parece ser maior para esse grupo, que muitas vezes perdem o interesse pelos estudos ou ingressam no mercado de trabalho em tempo integral.

Teoricamente, seria de se esperar efeitos diferenciados do PBF dependendo da faixa etária, realizamos o mesmo procedimento para outro recorte de idade como robustez. Para os jovens entre 17 e 21 anos, obtivemos os seguintes resultados:

Tabela 6 | Impactos do Bolsa Família sobre os jovens entre 17 e 21 anos de idade

\begin{tabular}{|c|c|c|c|c|c|c|c|c|c|}
\hline \multirow[t]{2}{*}{ VARIÁVEL } & \multicolumn{3}{|c|}{ Escolaridade } & \multicolumn{3}{|c|}{ Foi aprovado } & \multicolumn{3}{|c|}{ Frequenta escola } \\
\hline & (1) & (2) & (3) & (1) & (2) & (3) & (1) & (2) & (3) \\
\hline \multirow[t]{2}{*}{$\begin{array}{l}\text { Beneficiários* } \\
\text { Ano } 2004\end{array}$} & 0.051 & 0.066 & 0.244 & 0.009 & 0.010 & -0.026 & -0.015 & -0.017 & 0.003 \\
\hline & $(0.115)$ & $(0.100)$ & $(0.236)$ & $(0.009)$ & $(0.009)$ & $(0.020)$ & $(0.016)$ & (0.015) & $(0.041)$ \\
\hline \multirow[t]{2}{*}{$\begin{array}{l}\text { Beneficiários* } \\
\text { Ano } 2008\end{array}$} & 0.081 & $0.211^{* *}$ & $0.574^{* *}$ & 0.009 & 0.011 & 0.000 & -0.018 & -0.021 & -0.038 \\
\hline & $(0.111)$ & $(0.097)$ & $(0.238)$ & $(0.009)$ & $(0.010)$ & $(0.026)$ & $(0.016)$ & $(0.015)$ & $(0.045)$ \\
\hline \multirow[t]{2}{*}{$\begin{array}{l}\text { Beneficiários* } \\
\text { Ano } 2012\end{array}$} & $0.245^{*}$ & $0.395^{* * *}$ & $0.514^{*}$ & $0.020^{*}$ & $0.021^{*}$ & 0.016 & $-0.072^{* * *}$ & $-0.044^{* *}$ & -0.027 \\
\hline & $(0.136)$ & $(0.118)$ & $(0.307)$ & $(0.011)$ & $(0.011)$ & $(0.028)$ & $(0.020)$ & $(0.018)$ & $(0.050)$ \\
\hline \multirow[t]{2}{*}{ Beneficiários } & $0.260^{* * *}$ & $0.469 * * *$ & 0.162 & -0.005 & -0.004 & 0.010 & $0.149 * * *$ & $0.098^{* * *}$ & $0.067^{* *}$ \\
\hline & $(0.099)$ & $(0.080)$ & $(0.171)$ & $(0.006)$ & $(0.007)$ & $(0.013)$ & (0.011) & $(0.010)$ & $(0.028)$ \\
\hline \multirow[t]{2}{*}{ Constante } & $6.394^{* * *}$ & $1.989 * * *$ & $2.652^{* * *}$ & $0.955^{* * *}$ & $0.851^{* * *}$ & $0.993^{* * *}$ & $0.379^{* * *}$ & $2.249 * * *$ & $1.735^{* * *}$ \\
\hline & $(0.101)$ & $(0.221)$ & $(0.841)$ & $(0.004)$ & $(0.025)$ & $(0.088)$ & $(0.008)$ & $(0.043)$ & $(0.145)$ \\
\hline Dummies de Ano & Sim & Sim & Sim & Sim & Sim & Sim & Sim & Sim & $\operatorname{Sim}$ \\
\hline $\begin{array}{l}\text { Características } \\
\text { Demográficas }\end{array}$ & Não & Sim & Sim & Não & Sim & Sim & Não & Sim & $\operatorname{sim}$ \\
\hline $\begin{array}{l}\text { Características } \\
\text { Familiares }\end{array}$ & Não & Sim & Sim & Não & Sim & Sim & Não & Sim & Sim \\
\hline $\begin{array}{l}\text { Características } \\
\text { Domiciliares }\end{array}$ & Não & Não & Sim & Não & Não & Sim & Não & Não & $\operatorname{sim}$ \\
\hline Observações & 38936 & 37520 & 5251 & 21087 & 20195 & 2907 & 39362 & 37857 & 5310 \\
\hline$R^{2}$ & 0.04 & 0.23 & 0.21 & 0.00 & 0.01 & 0.02 & 0.02 & 0.17 & 0.18 \\
\hline
\end{tabular}

Fonte: PNAD/ IBGE - pesquisa domiciliar.

Nota: o conjunto de controles para características familiares e do chefe do domicílio é composto por: gênero, raça, idade, se o individuo trabalha, se tem mãe viva, se a mãe mora no domicílio; o conjunto de variáveis para o chefe de família inclui sexo, raça, escolaridade, e se trabalha. O conjunto com características do domicilio é composto por: água canalizada, banheiro, energia elétrica, saneamento básico, área, moradores de 6 a 17 anos, geladeira, máquina de lavar roupa e microcomputador.

Erros padrão robusto entre parênteses - * significante a $10 \%$;* significante a $5 \%$; *** significante a $1 \%$.

De fato, a variável escolaridade aparece maior e estatisticamente significante para os anos de 2008 e 2012 em relação ao grupo de não beneficiários, no entanto, a magnitude ainda é baixa, há um ganho de apenas 0,5 anos de estudos comparados aos não tratados. Uma hipótese para o resultado positivo em todos os anos é que essas crianças devem ter sido expostas a um maior tempo de tratamento, isto é, provavelmente estes indivíduos devem ter sido beneficiários do PBF durante o ensino fundamental. No que diz respeito à aprovação, esta se torna significativa para beneficiados apenas para o 
ano de 2012, com uma probabilidade de 2,2\% a favor dos beneficiários. A frequência escolar permaneceu menor e estatisticamente significante para esse grupo, reduzindo em $11,8 \%$ a probabilidade de frequentarem a escola, com exceção do ano de 2012, onde a variável deixou de ser significante.

Não encontramos resultados positivos no que diz respeito à frequência escolar, no entanto, sabemos que quanto maior a idade do individuo maior é o custo de oportunidade de estudar, ainda mais se tratando de famílias de baixa renda.

Os resultados mostram que o PBF não é efetivo em estimular de maneira significativa a acumulação de capital humano nas gerações mais velhas das famílias beneficiárias, os impactos sobre estes são muito tênues ou de pouca magnitude.

Entretanto, não podemos afirmar que o programa não surte efeito em sua condicionalidade no tocante à educação. Quando estudamos o grupo de indivíduos em uma faixa etária um pouco menor, podemos observar que há evidências de maior progressão escolar entre aqueles que residem em domicílios beneficiários quando comparados aos que não recebem o benefício.

Ainda há muitos desafios a serem enfrentados pelo PBF para alcançar um de seus objetivos precípuos, que é combater o ciclo de pobreza por meio da condicionalidade da frequência escolar. As famílias de baixa renda geralmente apresentam baixo background familiar que acaba sendo repassado entre gerações, o gráfico 2 mostra que a última série concluída com aprovação dentre os jovens entre 15 e 25 anos se refere ao ensino fundamental seguido do ensino médio.

Gráfico 2 | Última série concluída com aprovação para jovens com idade entre 15 e 25 anos

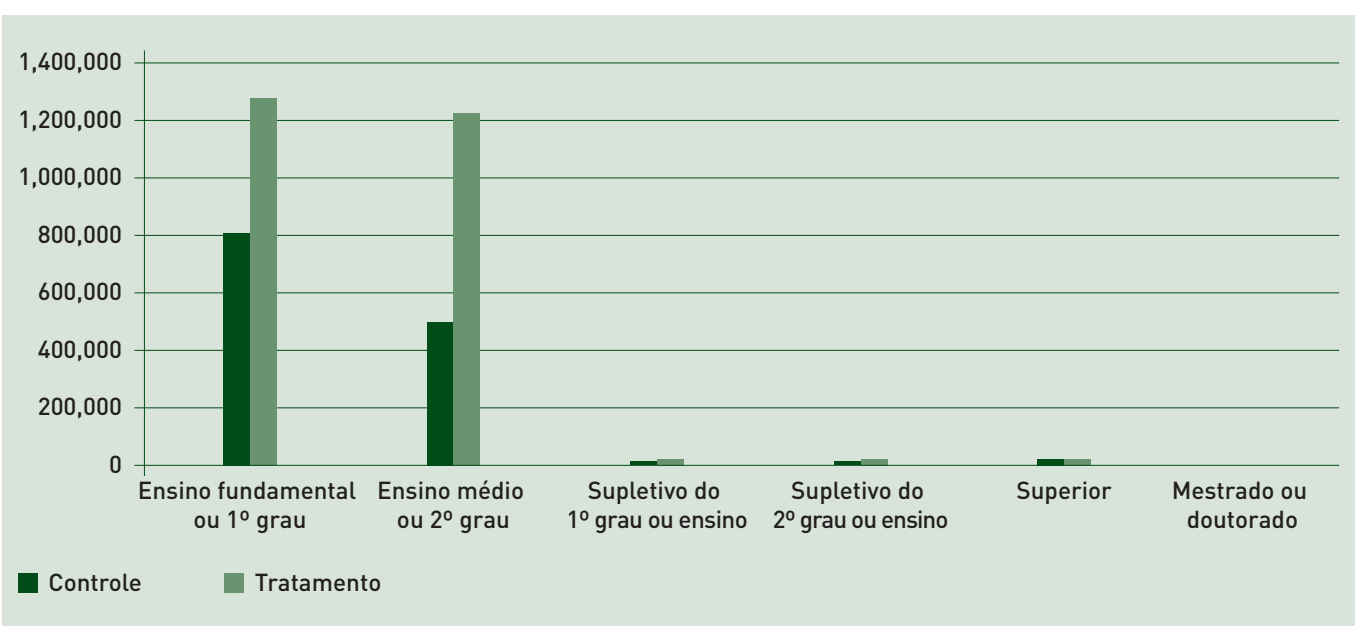

Fonte: Elaboração própria com base nos dados da PNAD do ano de 2012.

Um primeiro desafio está em criar condições para que jovens e adultos com mais de 17 anos, que participam do PBF, permaneçam na escola, tendo oportunidades para completar sua formação no ensino médio ou mesmo num curso de graduação. 
Os resultados encontrados nesse artigo através dos dados sobre escolaridade dos beneficiários do PBF indicam que, ao finalizar o período de exigência de frequência escolar definido pelo programa, caem abruptamente os números relativos à frequência escolar.

\section{CONCLUSÃO}

Os programas de transferência condicional de renda se destacam como estratégia política de combate à pobreza e redução da desigualdade. A principal condicionalidade dos programas adotada na América Latina é a exigência da matrícula e de uma frequência escolar mínima do aluno beneficiário. Busca-se através desse desenho, gerar maior acumulação de capital humano, promovendo assim, uma quebra no ciclo de pobreza entre gerações ao longo prazo.

O que os estudos vêm mostrando é que o benefício do PBF por meio de sua condicionalidade educacional tem um efeito significativo na inclusão escolar e permanência das crianças beneficiárias na escola.

Este trabalho analisou o impacto do PBF sobre a escolaridade, frequência escolar e aprovação dos jovens entre 15 e 25 anos de idade das famílias beneficiadas pelo programa. Não logramos indícios de aumentos na escolaridade para esses indivíduos pelo simples fato de residirem em domicílios beneficiados. No entanto, para o grupo de 17 a 21 anos de idade, encontrou-se impacto positivo e significativo dessa condicionalidade em favor dos beneficiados, uma das hipóteses é de que essas crianças foram expostas mais tempo ao tratamento.

A frequência escolar aparece negativa e significativa para ambos os grupos, isto ocorre porque o custo de oportunidade de se manter na escola aumenta proporcionalmente a idade, ainda mais se tratando de famílias de baixa renda.

Em geral, os resultados encontrados sobre tais variáveis foram pequenos no que diz respeito à acumulação de capital humano por parte dos jovens das famílias beneficiadas. O programa focalizado nas crianças deixa pouca margem para impacto em grupos com idade superior a 17 anos, idade limite para o cumprimento das condicionalidades. 


\section{REFERÊNCIAS}

BRASIL. Ministério do Desenvolvimento Social (MDS). Programa Bolsa-Família. Disponível em: < http://www.mds. gov.br/bolsafamilia>. Acesso em: 15 jun 2013.

CACCIAMALI, Maria Cristina; TATEI, Fábio; BATISTA Natália Ferreira. Impactos do Programa Bolsa Família Federal sobre o trabalho infantil e a freqüência escolar. Revista de Economia contemporânea, Rio de Janeiro, v. 14, n. 2 de Economia contemporânea, Rio de Janeiro, v. 14, n. 2,
p. 269-301, maio/ago. 2010. Disponível em: < http:/ / www. p. 269-301, maio/ago. 2010. Disponível em: < http://www.
scielo.br/scielo.php?pid=S1415-98482010000200003\&scri pt $=$ sci_arttext $>$. Acesso em: 25 jun 2013

CAMARGO, Pedro Cavalcante. Uma análise do efeito do programa Bolsa Família sobre o desempenho médio das escolas brasileiras. 2011. Dissertação (pós-graduação em escolas brasileiras. 2011. Dissertação (pós-graduação em
economia) - Universidade de São Paulo, Ribeirão Preto, economia) - Universidade de São Paulo, Ribeirão Preto,
2011. Disponível em: $<$ http://www.teses.usp.br/teses/di2011. Disponível em:<http://www.teses.usp.br/teses/di-
sponiveis/96/96131/tde-17042012-165751/pt-br.php>. Acesso em: 28 jun 2013

CAVALCANTI, Pedro Luiz Costa. Programas de Transferência Condicionada de Renda na América Latina: uma abordagem comparada entre Brasil, México, Chile e Colômbia. Serviço Público. Brasília, p. 105-118 Abr/Jun 2011. Disponível em: < http://www.periodicoseletronicos. ufma.br/index.php/rppublica/article/viewFile/29/17>. Acesso em: 28 mai 2013.

CIRENO, Flávio; SILVA, Joana; PROENCA, Rafael Prado. Condicionalidades, desempenho e percurso escolar de beneficiários do programa bolsa família. In: Programa Bolsa Família : uma década de inclusão e cidadania. Brasília: IPEA, 2013. p. 297-304

COHN, Amélia. Programas de transferência de renda e questão social no Brasil. Estudos e Pesquisas, n.85. Rio

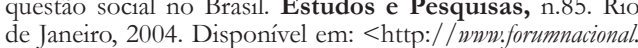
de Janeiro, 2004. Disponível em: <http:// mmm.forumnacional.
org.br/trf_arq.php?cod=EP00850> $\square$. Acesso em: 01 jul 2013.

COSTA, Alan André Borges; SALVATO, Marcio Antônio. Análise contrafactual do programa de transferência de renda bolsa família para o período 2004-2006. CEDEPLAR, 2008. Disponível em: < http://web.cedeplar.ufmg. PLAR, 2008. Disponível em: <http://web.cedeplar.ufmg.
br/cedeplar/site/seminarios/seminario diamantina/2008/ br/cedeplar/site/seminarios/seminario_c

FAHEL, Murilo Cássio Xavier; MORAIS, Thais; FRANÇA, Bruno Cabral. O impacto do bolsa família na inclusão Educacional: análise da matrícula escolar em Minas Gerais. SER Social, Brasília, v. 14, n. 30, p. 98-126, jan./ jun. 2012. Disponível em: <http://seer.bce.unb.br/index $\mathrm{php} /$ SER_Social/article/viewArticle/6913>. Acesso em: 25 jun 2013 .

FOGUEL, Miguel Nathan; BARROS, Ricardo Paes de. The effects of conditional cash transfer programmes on adult labour supply: an empirical analysis using a timeseries-cross-section. In: ENCONTRO NACIONAL DE ECONOMIA, 33., 2008, Salvador. Anais. Salvador: Anpec, 2008. Disponível em: < http://www.anpec.org.br/encontro2008/artigos/200807211655420-.pdf>. Disponível em 27 out 2013 .

FOGUEL, Miguel Nathan. Diferenças em Diferenças. In: Avaliação Econômica de projetos sociais/ Betânia In: Avaliação Econômica de projetos sociais/ Betania
Peixoto...[et al.]; organizador Naercio Menezes Filho. $-1^{\text {a }}$. Peixoto...[et al.]; organizador Naercio Menezes Filho. - $1^{\text {a }}$.
ed. - São Paulo: Dinâmica Gráfica e Editora, 2012. p. 69- 83.

GLEWWE, Paul.; KASSOUF, Ana Lúcia. O impacto do programa bolsa família no total de matrículas do ensino fundamental, taxas de abandono e aprovação. In: SILVA F. S. (Org.). I Prêmio e I Mostra Nacional de estudos sobre o Programa Bolsa Família. Brasília/DF: Ministério sobre o Programa Bolsa Família. Brasília/DF: Ministério
do Desenvolvimento Social, p. 41-56, 2008. Disponível em: $<$ http://www.ipcundp.org >. Acesso em: 27 jun 2013.
IBGE, PESQUISA NACIONAL POR AMOSTRA DE DOMICÍLIOS, micro dados. Elaboração própria.

INEP. Boletins de Estudos Educacionais do Inep. 2011. Disponível em: <http://download.inep.gov.br/download/ na_medida/BNMedida-ano3-N6-Jan2011.pdf>. Acesso em: 12 jun 2013 .

INSTITUTO BRASILEIRO DE ANÁLISES SOCIAIS E ECONÔMICAS, Repercussões do programa Bolsa Família na segurança alimentar e nutricional das famílias beneficiadas. Rio de Janeiro, 2008. Disponível em: <http://www ibase.br/userimages/ibase_bf_sintese_site.pdf. >. Acesso em: 28 nov 2013

JANUZZI, Paulo; PINTO, Alexandre. Bolsa Família e seus impactos nas condições de vida da população brasileira: uma síntese dos principais achados da Pesquisa de Avaliação de Impacto do Bolsa Família II. In: Programa Bolsa Família : uma década de inclusão e cidadania. Brasília: IPEA, 2013. p. 179-192.

LAVINAS, Lena. Pobreza e Exclusão: traduções regionais de duas categorias da prática. In: Revista Econômica, v.4, n.1, p.25-59, junho, 2002. Disponível em: < http://www. uff.br/revistaeconomica/v4n1/lavinas.pdf $>$. Acesso em: 28 nov 2013.

LAVINAS, Lena. Pobreza, Desigualdade e Exclusão: contextos atuais. Miméo, 75 páginas, UBRAL-10, Prefeitura de São Paulo -União Européia. Partes I e II, 2003. Disponível em: < http:// fonseas.org.br/novosite/wp-content/ uploads/2012/07/Pobreza-Desigualdade-e-Exclusao-contextos-atuais-Lena-Lavinas.pdf>. Acesso em: 30 nov 2013.

LEÃO REGO, Walquíria; PINZANI, Alessandro. Vozes do Bolsa Família. Autonomia, dinheiro e cidadania. São Paulo: Editora da UNESP, 2013.

MAGRO, Aline Fátima do Nascimento; REIS, Carlos Nelson. Os programas de transferência de renda na América Latina: panorama de experiências em desenvolvimento OIDLES. Vol5, N ${ }^{\circ} 10$, Junho 2011. Disponível em: < http:// OIDLES. Vol5, $\mathrm{N}^{\circ}$ 10, Junho 2011. Disponivel em: < http://
www.eumed.net/rev/oidles/10/nmnr.htm $>$. Acesso em: 03 jul 2013.

MDS. Avaliação de Impacto do Programa Bolsa Família - $2^{\text {a }}$ Rodada (AIBF II) Brasília, 2012. Disponível em <http://aplicacoes.mds.gov.br/sagi/PainelPEI/Publicacoes/Avaliacao de Impacto Programa Bolsa Familia II.pdf $>$. Acesso em: 16 jul 2013.

NASCIMENTO, Aline Fátima; REIS, Carlos Nelson. Os programas de transferência condicionada de renda na América Latina: especificidades de uma realidade que se mantém. Pol. Públ. São Luis, v. 13 n. 2, p. 183-193, jul. dez. 2009. Disponível em: < http://www.periodicoseletronicos.ufma.br/index.php/rppublica/article/viewFile/29/17. Acesso em: 14 jun 2013.

OLIVEIRA, Luís Felipe Batista; SOARES, Sergei S. D. Bolsa Família e repetência: resultados a partir do Cadúnico, projeto frequência e censo escolar. In: Programa co, projeto frequência e censo escolar. In: Programa IPEA, 2013. p. 285-295

PAIVA, Luis Henrique; FALCÃO, Tiago; BARTHOLO, Letícia. Do Bolsa Família ao Brasil sem miséria: um resumo do percurso brasileiro recente na busca da superação da pobreza extrema. In: Programa Bolsa Família: uma década breza extrema. In: Programa Bolsa Família: uma
de inclusão e cidadania. Brasília: IPEA, 2013. p. 25-46.

PELLEGRINA, Heitor Sandes. Impactos de curto prazo do programa bolsa família sobre o abandono e o desempenho escolar do aluno paulista. 2011. Dissertação (mestrado em economia) - FEA-USP, São Paulo, 2011. Disponível poniveis/12/12138/tde-26092011 165149/ptbr.php>. Acesso em: 30 jun 2013. 
SANTARROSA, Rogério Bianchi. Impacto das Transferências Condicionadas de Renda sobre a proficiência dos alunos do Ensino Fundamental no Brasil. 2011.Dissertação (mestrado em economia) - Fundação Getúlio Vargas, São Paulo, 2011. Disponivel em: <http://bibliotecadigital.fo br/dspace/handle/10438/8537>. Acesso em: 01 jul 2013.

SILVA, Anderson Paulino; BRANDÃO, André; DALT, Salete. Educação e pobreza: o impacto das condicionalidades do programa bolsa família. Revista Contemporânea de Educação, Rio de Janeiro, v.4, n. 8, p. 296-313, 2009. Disponível em: < http://www.revistacontemporanea.fe.ufri.br/ index.php/contemporanea/article/view/89/81>. Acesso em: 24 jun. 2013.

SOARES, Fábio Veras et al. Programas de Transferência de Renda no Brasil: Impactos sobre a Desigualdade. Texto para Discussão 1228. IPEA, Brasília, outubro de 2006. Disponível em: <http://www.ipea.gov.br/portal/index. php?option $=$ com_content $\&$ view $=$ article $\&$ id $=4374>$. Aces so em: 02 nov 2013.

SOARES, Sergei et al. Programas de Transferência condicionada de renda no Brasil, Chile e México: impactos sobre a desigualdade. Texto para Discussão $\mathrm{n}^{\circ}$ 1293. Brasília: IPEA, julho de 2007. Disponível em: $<$ http://www.ipea.gov.br/portal/index.php?option $=$ com content\&view=article\&id $=4852>$. Acesso em: 19 jun. 2013.

TAVARES, Priscila Albuquerque et al. Uma avaliação do Programa bolsa família: Focalização e impacto na distribuição de renda e pobreza. Ribeirão Preto [s.n.], 2009. Disponível em: <http://ppe.ipea.gov.br/index.php/ppe/ article/view/1062/1044>. Acesso em: 21 jun. 2013. 


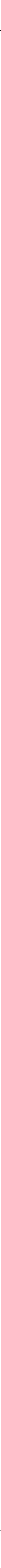

